Revista Oficial del Poder Judicial

ÓRGANO DE INVESTIGACIÓN DE LA CORTE SUPREMA DE JUSTICIA DE LA REPÚBLICA DEL PERÚ

Vol. 13, n. ${ }^{0} 16$, julio-diciembre, 2021, 191-239

ISSN: 1997-6682 (Impreso)

ISSN: 2663-9130 (En Línea)

DOI: 10.35292/ropj.u13i16.414

\title{
El derecho a vivir bien desde el sistema jurídico comunitario y su implicancia en el traslado de la ciudad de Cerro de Pasco, producto de los trabajos mineros a tajo abierto
}

\section{The right to live well, from the community legal system and its implication in the relocation of the city of Cerro de Pasco, as a result of open-pit mining works 00}

EdA DENISE PALACIOS CÁRDENAS Universidad Nacional Mayor de San Marcos (Lima, Perú)

Contacto: epalaciosc1@unmsm.edu.pe https://orcid.org/0000-0002-5616-4173

\section{RESUMEN}

El artículo resume el estudio realizado sobre la importancia de entender el vivir bien, tan conocido por nuestros pueblos ancestrales, como una forma de vida con y para la naturaleza y cómo su comprensión puede cimentar la planificación que permita el traslado de la población de Cerro de Pasco, ciudad nacida como minera, producto de sus inmensas vetas argentífiras y de qué forma 
este «milagro» natural se ha convertido en su propia destrucción. Durante más de un siglo se viene escribiendo sobre la urgencia de alojar a la población en un medio ambiente lejano a los trabajos mineros; sin embargo, la existencia de leyes no ha permitido concretar el ansiado sueño de vivir con dignidad, pues no importa que la salud de todos sus pobladores se menoscabe en la misma proporción en que se extraen los minerales. Asimismo, junto con la afectación al derecho a la salud, se afectan otros como el del patrimonio cultural, el medio ambiente, el desarrollo y la paz.

Palabras clave: sistema comunitario; buen vivir; traslado; minería; tajo abierto; paz, desarrollo; patrimonio cultural.

\section{ABSTRACT}

The article summarizes the study carried out on the importance of understanding living well, so well known by our ancestral peoples, as a way of life with and for nature and how its understanding can cement the planning that allows the relocation of the population of Cerro de Pasco, a city born as a mining town, product of its immense argentiferous veins, and how this natural «miracle» has become its own destruction. For more than a century, people have been writing about the urgency of housing the population in an environment far away from mining operations. However, the existence of laws has not allowed the longed-for dream of living with dignity to become a reality, because it does not matter that the health of all its inhabitants is undermined in the same proportion as the minerals are extracted. Likewise, together with the affectation of the right to health, other rights are affected, such as cultural heritage, environment, development, and peace.

Key words: community system; good living; relocation; mining; open pit; peace, development; cultural heritage.

Recibido: 12/08/2021 Aceptado: 16/10/2021 


\section{INTRODUCCIÓN}

\subsection{Situación de la ciudad de Cerro de Pasco}

Cumplido el bicentenario de nuestra independencia política, resulta poco glorioso el pensar cómo desde sus albores la ciudad de Cerro de Pasco ha tenido como destino su destrucción. Ni siquiera el haber sostenido la economía peruana, primero en la época colonial y continuar haciéndolo durante estos dos siglos de república, ha permitido que escape de ello. Pareciera sencillo el pensar que la destrucción de viviendas, edificios públicos, monumentos, etc., solo significaría terminar con frías construcciones de hierro o cemento; sin embargo, ello implica la extinción de siglos de cultura, de tradiciones, de costumbres.

Durante ciertos períodos de gobiernos y a tenor de los vientos del pensamiento de la época se fueron ideando formas de trasladar la ciudad, entendiéndose claramente que el trabajo minero no cesaría, incluso se intensificó con el sistema a tajo abierto; curiosa es la antípoda que se presenta, las vetas mineras parecen inacabables, pero la ciudad se termina apresuradamente.

Así, a inicios del siglo XX se dieron los primeros gritos de un necesario traslado de los pobladores, y es durante el gobierno militar de Juan Velasco Alvarado que se promulga el Decreto Ley n. ${ }^{\circ}$ 18863, que autoriza el traslado de la ciudad de Cerro de Pasco a la denominada nueva ciudad de San Juan Pampa o Pampa de San Juan; este decreto ley fue reglamentado mediante el Decreto Supremo n. ${ }^{\circ}$ 106-82-VI. Sin embargo, la antigua ciudad de Cerro de Pasco nunca dejó de ser habitada, incluso en los últimos veinte años se han venido construyendo viviendas alrededor del tajo abierto o de los cerros de minerales; muy a pesar de que el 13 de diciembre de 2008 se promulgó la Ley n. ${ }^{\circ} 29293$, «Ley que declara de necesidad pública e interés nacional la implementación de medidas para lograr el desarrollo urbano sostenible concertado y la reubicación de la ciudad de Cerro de Pasco». 
Mucho se habla en teoría del desarrollo sostenible y en los últimos años se han promulgado leyes respecto a la protección del medio ambiente, nuestra carta magna en su catálogo de derechos humanos tiene al derecho a la salud como inmanente al ser humano. Sin embargo, en la ciudad de Cerro de Pasco día a día se incrementa el nivel de plomo en sangre de sus pobladores y los niños tienen problemas de salud y dificultades de aprendizaje, en medio del incansable trabajo minero, que con desgano formula informes que socaban su accionar, nada de ello con miras de reparar el daño causado.

Dentro de todo esto, que parece poco o nada esperanzador, surge la idea de rescatar el derecho con el que se han desenvuelto nuestros ancestros y con el cual, a pesar de siglos de opresión, lo siguen haciendo nuestras comunidades campesinas y amazónicas: el vivir en torno al respeto de las leyes de la naturaleza, el comprenderse como individuo y como parte del todo, el volver al equilibrio con la pachamama: el derecho a vivir bien.

El derecho a vivir bien se entiende como una necesaria forma de vivir, donde el respeto a la vida, a la salud y en general el respeto de cada integrante de la comunidad, de la sociedad, permitirá buscar un medio adecuado para los pobladores de la ciudad de Cerro de Pasco y, a su vez, se buscará que el derecho a la paz, al desarrollo, al patrimonio cultural, al medio ambiente también sean respetados.

\section{EL DERECHO A VIVIR BIEN}

\subsection{Filosofía andina}

No existe otra forma de comprender el derecho a vivir bien si no es entendiendo el sistema social y luego jurídico de las poblaciones indígenas, llamadas ahora comunidades; por ello se hace necesario razonar desde el punto de vista de la filosofía andina y cómo esta se ha ido desarrollando en el entendimiento de la naturaleza, de la 
geografía, de los ciclos del agua, del sol, de la luna. Fue su comprensión de la naturaleza lo que les permitió asentar los primeros grupos humanos y desarrollar posteriormente relaciones con ella misma y entre los hombres.

Taipe (1992) nos dice que con el tiempo esto los llevó a establecer componentes científicos y tecnológicos en los campos de la agricultura, ganadería, comercio, arquitectura, cerámica, textilería, escultura, minería, metalurgia, hidráulica, agrotecnia, ecología, medicina, geografía, astronomía, matemática, física, geometría, urbanística, ciudadanía, comunicaciones, canto, música, danza, historia, literatura, moral, jurisprudencia, etc.; cuya complejidad y profundidad son aún un misterio para la ciencia y tecnología moderna.

Los conceptos de la filosofía andina se resumen en:

a) Sabiduría sobre singularidad (Chullachasqakay).

b) Sabiduría sobre relacionaidad (Tinkinakuy).

c) Sabiduría sobre correspondencia (Kaqnin).

d) Sabiduría sobre simetría (Qinakay).

e) Sabiduría sobre afinidad (Munaykuyay).

f) Sabiduría sobre paridad (Yanatin).

g) Sabiduría sobre unidad (Hukchallay).

h) Sabiduría sobre proporcionalidad (Kaq qinakay).

i) Sabiduría sobre complementariedad (Ayni).

j) Sabiduría sobre vincularidad (Tinkuy).

k) Sabiduría sobre vida (Kawsay).

1) Sabiduría sobre trascendencia del dominio común (Ninchik)

m) Sabiduría sobre realidad aparente (Pantasqaqina) (Taipe, 1992, pp. 60-107).

\subsection{Cosmovisión}

La Coordinadora Andina de Organizaciones Indígenas (CAOI) (2010) sobre este particular señala: 
Los abuelos y abuelas de los pueblos ancestrales hicieron florecer la cultura de la vida inspirados en la expresión del multiverso, donde todo está conectado, interrelacionado, nada está fuera, sino por el contrario «todo es parte de...»; la armonía y equilibrio de uno y del todo es importante para la comunidad.

Es así que en gran parte de los pueblos de la región andina de Colombia, Ecuador, Bolivia, Perú, Chile y Argentina, y en los pueblos ancestrales (primeras Naciones) de Norteamérica pervive la Cosmovisión Ancestral o Visión Cósmica, que es una forma de comprender, de percibir el mundo y expresarse en las relaciones de vida. Existen muchas naciones y culturas en el Abya Yala, cada una de ellas con sus propias identidades, pero con una esencia común: el paradigma comunitario basado en la vida en armonía y el equilibrio con el entorno (p. 24).

\subsection{Definición del buen vivir}

El expresidente de Bolivia Evo Morales nos refiere, en cuanto a la definición del buen vivir, lo siguiente:

El Vivir Bien es vivir en igualdad y en justicia. Donde no haya ni explotados ni explotadores, donde no haya excluidos ni quienes excluyan, donde no haya marginados, donde no haya marginados ni marginadores. El Vivir Bien es vivir en comunidad, en colectividad, en reciprocidad, en solidaridad, y, especialmente, en complementariedad.

El Vivir Bien no es lo mismo que el vivir mejor, el vivir mejor que el otro. Porque para el vivir mejor, frente al prójimo, se hace necesario explotar, se instala la competencia, se concentra la riqueza en pocas manos. Entonces se produce una profunda competencia, unos quieren vivir mejor y esto a cambio de que otros, las mayorías, vivan mal. Ahí hay una gran diferencia, ya que el Vivir Bien es vivir en igualdad de condiciones, vivir mejor es egoísmo, desinterés por los demás, individualismo (Ministerio de Relaciones Exteriores del Estado Plurinacional de Bolivia, 2010 p. 9). 
Ahora bien, se hace necesario describir la concepción de vivir bien en algunas comunidades sudamericanas:

- Para el pueblo aimara-quechua de Bolivia, el vivir bien significa desenvolvernos en armonía con todos y todo, apuntando a reducir la adicción al consumo y mantener una producción equilibrada sin arruinar el entorno en el que vivimos.

- Para el pueblo mapuche de Chile, que también asume la cosmovisión andina, el vivir bien también es vivir sin violencia, con afecto y empatía.

- El pueblo kolla de Argentina también comparte los principios de vida en armonía y comunidad, propios de la filosofía indígena.

- Para los pueblos amazónicos, el vivir bien es «volver a la maloca», es no ser un ser individual sino colectivo, viviendo en el tiempo circular del gran retorno, donde el futuro está siempre atrás, es el porvenir, el presente y el pasado delante de uno, con sus enseñanzas y las lecciones individuales y colectivas del proceso de vida inmemorial (CAOI, 2010).

\subsection{Derechos de los pueblos indígenas interrelacionados con el derecho a vivir bien}

\subsubsection{Derecho a la paz}

De acuerdo con Montañés y Ramos (2012):

La paz y el conflicto son realidades socioculturales construidas, por tanto, se ha de propiciar la participación de los sujetos en la gestión de los conflictos y la construcción de la paz [...] se relaciona directamente el concepto paz con la ausencia de enfrentamientos $\operatorname{armados}$ (p. 242).

Es lo que se ha denominado la paz negativa. 


\subsubsection{Derecho al desarrollo}

Sobre el derecho al desarrollo Díaz Müller (2004) indica que es

un derecho inalienable, acumulativo - reforzamiento de los derechos civiles, políticos, sociales, económicos y culturales y refuerzo de su independencia e indivisibilidad-, progresivo - persigue el bienestar y la justicia social- de alcance internacional, su aplicación es compleja y multifacética - que requiere de mecanismos idóneos para su eficacia y su aplicación es polifacética dada la titularidad singular y plural de los sujetos del derecho-, es promotor de un nuevo orden mundial, posee una finalidad teleológica - guía modelos de desarrollo y análisis como ha sido el índice de desarrollo humano- (citado por Ruiz, 2016, p. 389).

\subsubsection{Derecho al medio ambiente}

Sobre este particular, Enrique Sotomayor Trelles y Fiorella Atay Calla (2018) detallan que la relación medio ambiente y derechos humanos ha sido materia de análisis de los órganos del sistema interamericano. En efecto, la CIDH y la Corte IDH han desarrollado importantes contenidos sobre este, a partir del conocimiento de casos sobre vulneraciones a pueblos indígenas y tribales como del impacto en los recursos naturales. De esta manera, el análisis del derecho al medio ambiente se dio atendiendo a una relación de interdependencia e indivisibilidad, característica de los derechos humanos y que, a su vez, ha permitido un amplio desarrollo jurisprudencial de la protección indirecta de los derechos económicos, sociales y culturales a través de los derechos civiles y políticos. Un claro ejemplo, como se ha señalado, es la jurisprudencia interamericana en materia de pueblos indígenas y tribales.

\subsubsection{Derecho al patrimonio cultural}

Al respecto Oscar Alberto Pérez Peña (2018) nos dice:

Desde el punto de vista jurídico, el concepto o definición de patrimonio cultural, elevado a categoría jurídica, está muy relacionado 
al criterio del valor cultural como requisito previo para la protección por dicho sistema jurídico en cuestión.

La noción de «patrimonio cultural»o «bienes culturales» proviene del primer empleo del término «bien cultural» en la Convención de La Haya de 1954 convocada por la UNESCO, y conocida también por Convención para la protección de los bienes culturales en caso de conflicto armado. La necesidad de superar el concepto de «monumento» de forma que se integraran a la protección todos los objetos anteriormente relegados, dio lugar a la formulación y desarrollo durante la segunda mitad del siglo XX, del concepto moderno de «bien cultural», aunque en este período, pero tempranamente, se promulgara la Carta Internacional para la Conservación y Restauración de Monumentos, o Carta de Venecia de 1964, que ofrece una noción de monumentos a su efecto en el artículo $1^{\circ}$. Se suma a esto, que La Comissione Francheschini de Italia, entre 1964 y 1967, reconoció como bien cultural en el orden jurídico «todo bien que constituya un testimonio material dotado de valor de civilización» (pp. 198-199).

\subsection{Jurisprudencia del Tribunal Constitucional sobre los derechos de los pueblos indígenas}

Tema: Derechos económicos, sociales y culturales Subtema: Derechos sociales-derechos fundamentales Resolución: N. ${ }^{\circ}$ 2002-2006-CC/TC Fecha de publicación: 27/06/2006

Caso: Pablo Miguel Fabían Martínez y otros

Sumilla: Los derechos sociales son derechos fundamentales por su relación e identificación con la dignidad de la persona y porque así se encuentran consagrados en nuestra Constitución. El Tribunal precisa que la exigibilidad se constituye en una categoría vinculada a la efectividad de los derechos fundamentales, pero no determina si un derecho es fundamental o no (ff. jj. 13 y 14).

URL: http://tc.gob.pe/jurisprudencia/2006/02002-2006-AC.pdf 
Tema: Derechos económicos, sociales y culturales

Subtema: Derechos sociales-concepto

Resolución: N. ${ }^{\circ}$ 2016-2004-AA/TC

Fecha de publicación: 08/04/2005

Caso: José Luis Correa Condori

Sumilla: Son facultades que protegen favoreciendo a aquellos grupos de personas cuyas circunstancias de vida representan una desventaja por razones económico sociales, situaciones que no son acordes con la dignidad humana (f. j. 9).

URL: http://www.tc.gob.pe/jurisprudencia/2005/02016-2004-AA.pdf

\section{Tema: Derecho al medio ambiente equilibrado}

Subtema: Desarrollo sostenible o sustentable

Resolución: N. ${ }^{\circ}$ 1206-2005-AA/TC

Fecha de publicación: 24/05/2007

Caso: INRENA

Sumilla: Las obligaciones impuestas tanto a particulares como al Estado, destinadas al cuidado y preservación del ambiente, no solo pretenden conservar el ambiente para el goce inmediato de la ciudadanía, sino que este cuidado se extiende a la protección del disfrute de las generaciones futuras, fundamento del concepto de desarrollo sostenible (f. j. 4).

URL: http://www.tc.gob.pe/jurisprudencia/2007/01206-2005-AA.pdf

\section{Tema: Derecho al medio ambiente equilibrado}

\section{Subtema: Desarrollo sostenible o sustentable}

Resolución: N. ${ }^{\circ}$ 2002-2006-CC/TC

Fecha de publicación: 27/06/2006

Caso: Pablo Miguel Fabián Martínez y otros

Sumilla: El principio de desarrollo sostenible o sustentable constituye una pauta basilar para que la gestión humana sea capaz de 
generar una mayor calidad y mejores condiciones de vida en beneficio de la población actual, pero manteniendo la potencialidad del ambiente para satisfacer las necesidades y las aspiraciones de vida de las generaciones futuras (f. j. 31).

URL: http://tc.gob.pe/jurisprudencia/2006/02002-2006-AC.pdf

\section{Tema: Derecho al medio ambiente equilibrado}

Subtema: Desarrollo sostenible o sustentable

Resolución: N.o 0048-2004-PI/TC

Fecha de publicación: 01/04/2005

Caso: Ley n. ${ }^{\circ}$ 28258, Ley de Regalía Minera

Sumilla: El principio de desarrollo sostenible o sustentable constituye una pauta basilar para que la gestión humana sea capaz de generar una mayor calidad y condiciones de vida en beneficio de la población actual, pero manteniendo la potencialidad del ambiente para satisfacer las necesidades y las aspiraciones de vida de las generaciones futuras (f. j. 19).

URL: http://www.tc.gob.pe/jurisprudencia/2005/00048-2004-AI.pdf

\section{Tema: Derecho al medio ambiente equilibrado}

\section{Subtema: Política nacional ambiental}

Resolución: N. ${ }^{\circ}$ 3510-2003-AA/TC

Fecha de publicación: 30/06/2005

Caso: Julio César Huayllasco Montalva

Sumilla: A través de esta política, el Estado concreta su obligación de desempeñar programas que impliquen actividades que tiendan a preservar y conservar el ambiente, y así poder asegurar el desarrollo integral de las futuras generaciones de peruanos (f. j. 2.f).

URL: http://www.tc.gob.pe/jurisprudencia/2005/03510-2003-AA.pdf 


\section{Tema: Derecho al medio ambiente equilibrado}

\section{Subtema: Política nacional ambiental}

Resolución: N. ${ }^{\circ}$ 0048-2004-PI/TC

Fecha de publicación: 01/04/2005

Caso: Ley n. ${ }^{\circ}$ 28258, Ley de Regalía Minera

Sumilla: Se delimitan las obligaciones del Estado que se derivan de la política nacional del ambiente (ff. jj. 31-33).

URL: http://www.tc.gob.pe/jurisprudencia/2005/00048-2004-AI.pdf

\section{Tema: Derecho al medio ambiente equilibrado}

\section{Subtema: Naturaleza}

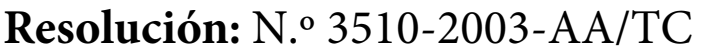

Fecha de publicación: 30/06/2005

Caso: Julio César Huayllasco Montalva

Sumilla: Se ha afirmado la naturaleza reaccional y prestacional del derecho a un ambiente equilibrado. Con relación al primer aspecto, se entiende que el derecho a un ambiente equilibrado exige que el Estado se abstenga de realizar actividades de degradación que afecten el ambiente. Por su parte, el aspecto prestacional exige del Estado que implemente políticas de prevención y de conservación del ambiente (f. j. 2.c).

URL: http://www.tc.gob.pe/jurisprudencia/2005/03510-2003-AA.pdf

\section{Tema: Derecho al medio ambiente equilibrado}

Subtema: Responsabilidad social

Resolución: N. ${ }^{\circ}$ 0048-2004-PI/TC

Fecha de publicación: 01/04/2005

Caso: Ley n. ${ }^{\circ} 28258$, Ley de Regalía Minera

Sumilla: Se precisa que la responsabilidad social implica la generación de actitudes y comportamientos de los agentes económicos y el establecimiento de políticas de promoción y el desarrollo de 
actividades que, en función del aprovechamiento o uso de los bienes ambientales, procuren el bien común y el bienestar general (ff. jj. 22-26).

URL: http://www.tc.gob.pe/jurisprudencia/2005/00048-2004-AI.pdf

\section{METODOLOGÍA Y RESULTADOS}

\subsection{Planteamiento del problema}

\subsubsection{Formulación del problema}

En la presente investigación se ha formulado como problema general: ¿cuáles son los derechos indígenas u originarios que se afectarían al no aplicarse el derecho a vivir bien, desde el sistema jurídico comunitario, en la reubicación de la ciudad de Cerro de Pasco por efectos de la minería a tajo abierto?

Asimismo, como problemas específicos:

a) ¿Cómo el derecho a la consulta previa puede garantizar el derecho a vivir bien en la reubicación de la ciudad de Cerro de Pasco por efectos de la minería a tajo abierto?

b) ¿Cómo el derecho al consentimiento libre e informado puede garantizar el derecho a vivir bien en la reubicación de la ciudad de Cerro de Pasco por efectos de la minería a tajo abierto?

Ante ello se ha propuesto la siguiente hipótesis general: los derechos indígenas u originarios que se afectarían al no aplicarse el derecho a vivir bien, desde el sistema jurídico comunitario, en la reubicación de la ciudad de Cerro de Pasco por efectos de la minería a tajo abierto, son el derecho a la salud, el derecho al patrimonio cultural, el derecho al medio ambiente, el derecho al desarrollo, el derecho a la paz, el derecho a la identidad y el derecho a la salud. 
De otro lado, las hipótesis específicas planteadas son las siguientes:

a) El derecho a la consulta previa garantizará el derecho a vivir bien en la reubicación de la ciudad de Cerro de Pasco por efectos de la minería a tajo abierto.

b) El derecho al consentimiento libre e informado garantizará el derecho a vivir bien en la reubicación de la ciudad de Cerro de Pasco por efectos de la minería a tajo abierto.

En esa misma línea, se ha establecido como objetivo general: establecer cuáles son los derechos indígenas u originarios que se afectarían al no aplicarse el derecho a vivir bien, desde el sistema jurídico comunitario, en la reubicación de la ciudad de Cerro de Pasco por efectos de la minería a tajo abierto; y como objetivos específicos: identificar de qué modo el derecho a la consulta previa puede garantizar el derecho a vivir bien en la reubicación de la ciudad de Cerro de Pasco por efectos de la minería a tajo abierto y constatar cómo el derecho al consentimiento libre e informado puede garantizar el derecho a vivir bien en la reubicación de la Ciudad de Cerro de Pasco por efectos de la minería a tajo abierto.

\subsection{Metodología aplicada}

\subsubsection{Tipo y diseño de inuestigación}

Tipo: jurídico-normativo.

Tipo o alcance: explicativo, aplicativo y transeccional.

Diseño de la investigación: simple, aleatorio y no estratificado; no experimental (no se manipulan variables); transeccional (años fijados para el estudio). 
El esquema es el siguiente:
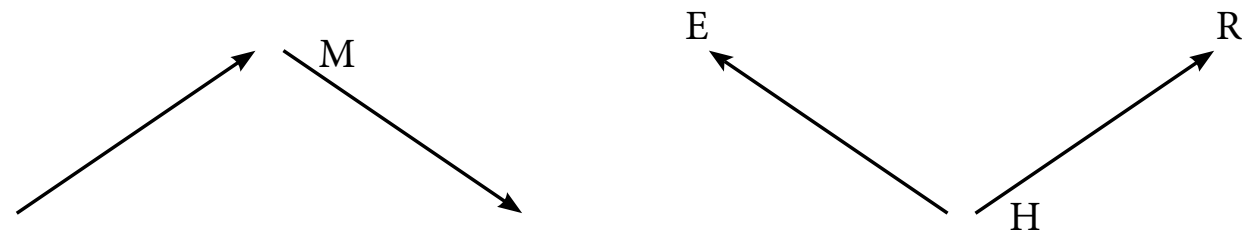

Donde:

E: encuesta

M: muestra

$\mathrm{R}$ : resultado

$\mathrm{H}$ : validación de hipótesis

Unidad de análisis: 366 pobladores de la ciudad de Cerro de Pasco.

Población de estudio: la población de la ciudad de Cerro de Pasco, a la fecha con 8000 ciudadanos.

Tamaño de la muestra: el tamaño de la muestra deberá ser representativa y debe garantizar validez y confiabilidad a fin de que los resultados sean inferidos a los demás elementos de la población con un mínimo margen de error. Para esto se aplicará la fórmula correspondiente, como se verá en el siguiente ítem. En el presente, la muestra es simple al azar, ya que se conciben todos los elementos como homogéneos.

La muestra se obtendrá mediante la siguiente fórmula estadística:

$$
\mathrm{n}=\frac{(Z)^{2}(P Q N)}{(E)^{2}(N-1)+(Z)^{2} P Q}
$$

Donde:

$\mathrm{Z}=$ Desviación estándar

$\mathrm{E}=$ Error de muestreo

$\mathrm{P}=$ Probabilidad de ocurrencia de los casos

$\mathrm{Q}=1-\mathrm{P}$

$\mathrm{N}=$ Tamaño del universo de la población 
Los valores estadísticos constantes para determinar el tamaño de una muestra estadísticamente significativa:

$$
\begin{aligned}
& Z=1.96(95 \%) \\
& E=0.05(5 \%) \\
& P=0.51(50 \%)
\end{aligned}
$$

Así tenemos:

$$
\begin{aligned}
& \mathrm{n}=\frac{\mathrm{n}(1.96)^{2}(0.5 \times 0.5) 8000}{(0.05)^{2}(8000-1)+(1.96)^{2}(0.5 \times 0.5)} \\
& \mathrm{n}=\frac{3.8416(0.25 \times 8000)}{0.0025(7999)+3.8416(0.25)} \\
& \mathrm{n}=\frac{3.8416(2000)}{19.9975+0.9604} \\
& \mathrm{n}=\frac{7683.2}{20.9579} \\
& \mathrm{n}=366.60
\end{aligned}
$$

\subsubsection{Selección de la muestra}

Según aconsejan Hernández Sampieri et al. (2018), es necesario aplicar la fórmula de la media aritmética a fin de tener una muestra provisional y otra definitiva. Cabe señalar que la muestra será simple y aleatoria sin reemplazo.

Debemos recurrir a las siguientes fórmulas:

$$
\begin{aligned}
& n^{\prime}=\frac{S^{2}}{V^{2}} \quad \begin{array}{l}
\text { Con la finalidad de establecer el tamaño provisional } \\
\text { de la muestra. }
\end{array} \\
& n=\frac{n^{\prime}}{1+\frac{n^{\prime} \mathrm{I}}{N}} \text { Para lograr la cantidad exacta de la muestra. }
\end{aligned}
$$




\subsubsection{Técnicas de recolección de datos}

Se aplicarán los instrumentos de recolección de datos (estadísticas, encuestas, entrevistas, revisión documental), los cuales deberán ser registrados. Así, en síntesis, tenemos:

Técnicas: a) observación, b) fichado, c) entrevista, d) encuesta, e) trabajo de campo, f) sistematización y g) trabajo en gabinete.

Instrumentos: fichas, encuestas, hojas de cotejo, reporteras, libreta de campo.

\subsection{Análisis e interpretación de la información}

Las páginas siguientes contienen cuadros y gráficos que, luego del trabajo de sistematización, análisis y aplicación estadísticos, en primer orden presentan datos porcentuales consolidados a partir de las respuestas logradas. Con el objeto de establecer concordancia gráfica dichos datos están acompañados por sus respectivos gráficos circulares.

Estos cuadros y gráficos corresponden a respuestas obtenidas y los subítems según sea el caso. Está compartido en tres secciones:

1. Información de las unidades de análisis.

2. Información de la identidad telúrica.

3. Información sobre las implicancias de la minería a tajo abierto en los derechos de la población de Cerro de Pasco.

Cada gráfico es materia de interpretación que, como se verá finalmente, conlleva a sostener y validar nuestras hipótesis. 


\subsubsection{De las unidades de análisis}

Cuadro y gráfico n. ${ }^{0} 1$

\section{Edad}

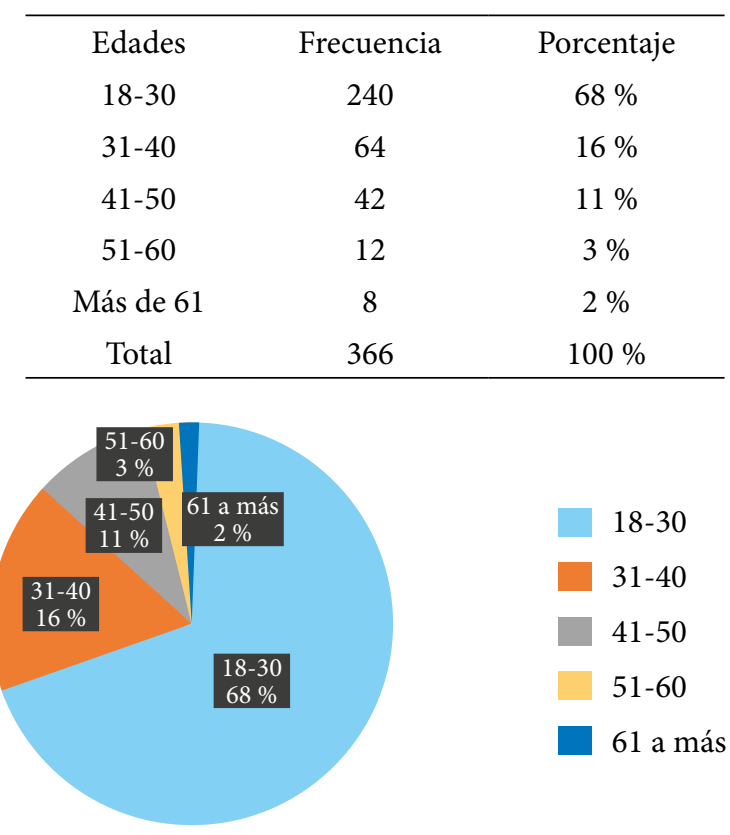

Fuente: Equipo de investigación.

Interpretación: En la población encuestada se observa que el mayor porcentaje (68\%) está entre 18 a 30 años; en el otro extremo, se tiene solo $2 \%$ de personas con más de 60 años. En consecuencia, la población de Cerro de Pasco es bastante joven.

\section{Cuadro y gráfico n. ${ }^{\circ} 2$}

\section{Sexo}

\begin{tabular}{ccc}
\hline Sexo & Frecuencia & Porcentaje \\
Masculino & 183 & $50 \%$ \\
Femenino & 181 & $49 \%$ \\
Otros & 2 & $1 \%$ \\
Total & 366 & $100 \%$ \\
\hline
\end{tabular}




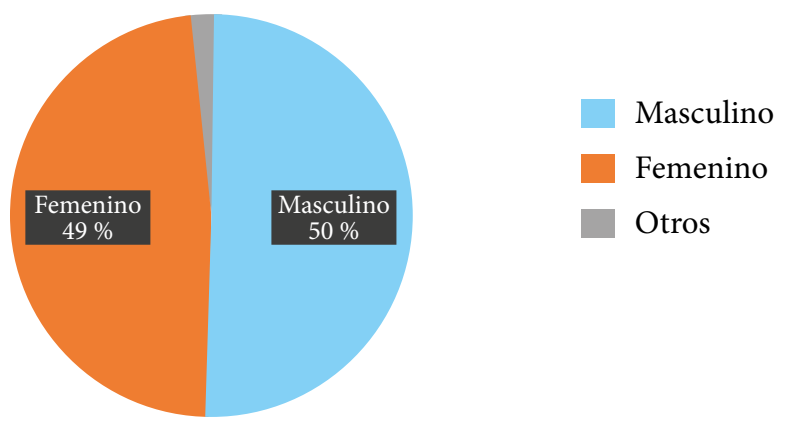

Fuente: Equipo de investigación.

Interpretación: Al igual que los datos nacionales respecto a la distribución por sexo, en esta ciudad también se repiten los porcentajes. Como caso particular, ya se vienen presentando manifestaciones sobre tendencias diferentes a pertenecer a la población masculina o femenina.

Cuadro y gráfico n. ${ }^{\circ} 3$

\section{Región de procedencia}

\begin{tabular}{ccc}
\hline Región & Frecuencia & Porcentaje \\
Pasco & 249 & $68 \%$ \\
Junín & 64 & $17 \%$ \\
Huánuco & 39 & $11 \%$ \\
Otra & 14 & $4 \%$ \\
Total & 366 & $100 \%$ \\
\hline & & \\
$17 \%$ & & \\
$11 \%$ & Pasco \\
& & Junín \\
& & Huánuco \\
& & \\
& &
\end{tabular}

Fuente: Equipo de investigación. 
Interpretación: La población mayoritaria (68\%) procede de la región Pasco, lo cual nos permite afianzar la confiabilidad en el sentido de que las siguientes interrogantes serán respondidas por un gran sector que conoce la idiosincrasia y la cultura de Cerro de Pasco.

Cuadro y gráfico n. ${ }^{\circ} 4$

Años de residencia en Cerro de Pasco

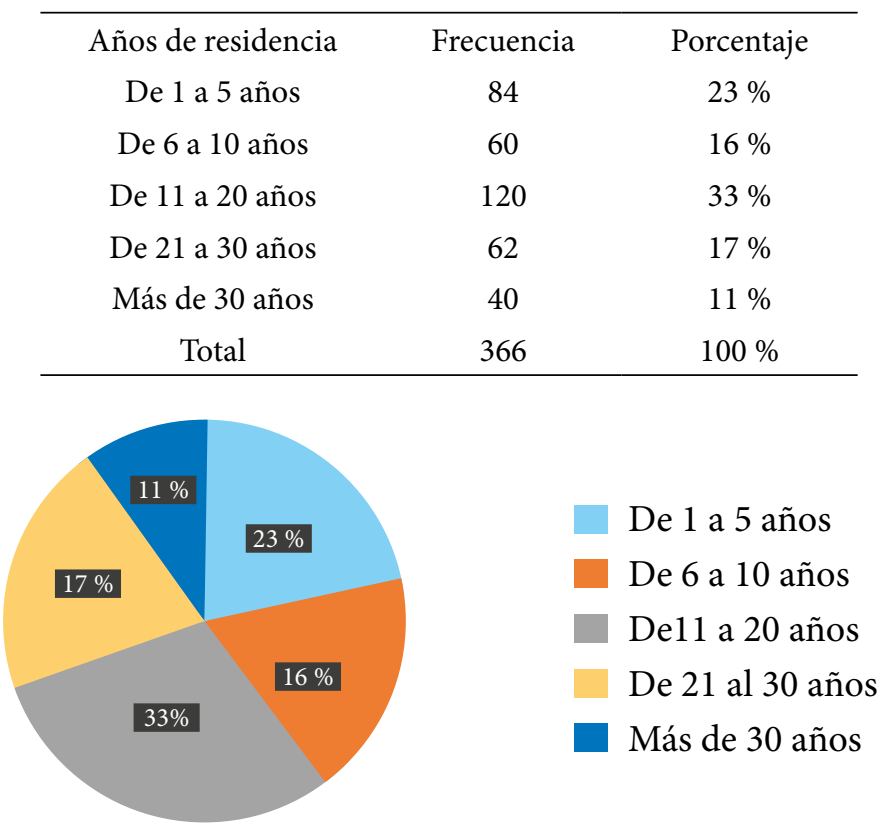

Fuente: Equipo de investigación.

Interpretación: De acuerdo con la interpretación sostenida en el cuadro y gráfico n. ${ }^{\circ} 3$, debe entenderse que el mayor porcentaje corresponde a Pasco como la región de origen, mientras que en el presente caso, el 33 \% agrupa a ciudadanos con tiempo de residencia en Cerro de Pasco. Esta información coadyuva a confirmar que estamos trabajando con un grupo de ciudadanos que tienen el tiempo necesario de convivencia para declarar con mucho acierto sobre las características socioculturales de esta ciudad. 


\section{Cuadro y gráfico n. ${ }^{\circ} 5$}

\section{Nivel educativo}

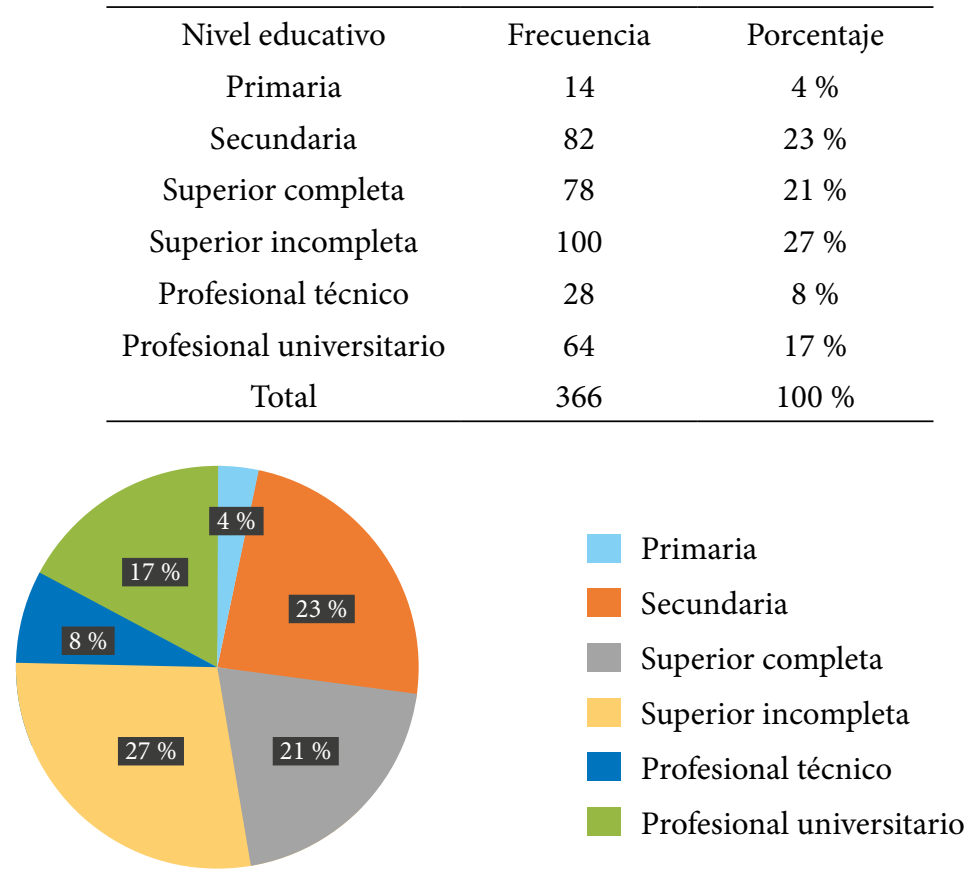

Fuente: Equipo de investigación.

Interpretación: $\mathrm{Si}$ acumulamos los porcentajes de educación superior incompleta, superior completa, profesionales técnicos y universitarios, obtenemos $73 \%$. Esto nos indica que los encuestados son personas con preparación académica, lo que garantiza sus respuestas.

\section{Cuadro y gráfico n. ${ }^{\circ} 6$}

\section{Tipo de vivienda}

\begin{tabular}{ccc}
\hline Tipo de vivienda & Frecuencia & Porcentaje \\
Propia & 244 & $62 \%$ \\
Alquilada & 114 & $36 \%$ \\
$\begin{array}{c}\text { Proporcionada por la } \\
\text { empresa }\end{array}$ & 8 & $2 \%$ \\
Total & 366 & $100 \%$ \\
\hline
\end{tabular}




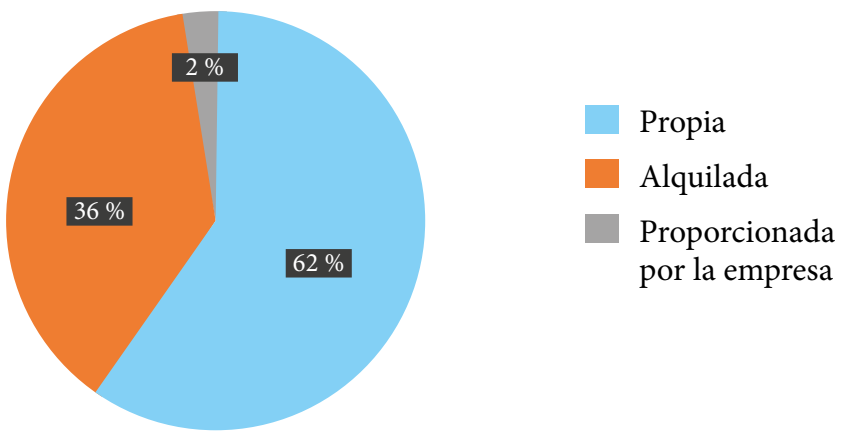

Fuente: Equipo de investigación.

Interpretación: A partir de 1990 la empresa minera Volcan S. A. C. rompe los convenios colectivos por los que estaba obligada a proporcionar vivienda a sus servidores. Aparecen los bonos económicos para que los trabajadores de la empresa adquieran terrenos y constituyan sus viviendas. Es la época de la aparición de pueblos jóvenes y asentamientos humanos. Efectivamente, si el 62 \% manifiesta que posee vivienda propia, se debe a este fenómeno. Serán materia de otro estudio los problemas posteriores que acarrearán las invasiones, la carencia de servicios básicos, etc.

\section{Cuadro y gráfico n. ${ }^{\circ} 7$}

\section{Ocupación}

\begin{tabular}{ccc}
\hline Ocupación & Frecuencia & Porcentaje \\
$\begin{array}{c}\text { Servidor dependiente } \\
\text { (empleado, autoridad, etc.) }\end{array}$ & 82 & $22 \%$ \\
$\begin{array}{c}\text { Independiente (comerciante, } \\
\text { taxista, etc.) }\end{array}$ & 76 & $21 \%$ \\
Trabajador eventual & 98 & $27 \%$ \\
Desocupado & 110 & $30 \%$ \\
Total & 366 & $100 \%$ \\
\hline
\end{tabular}




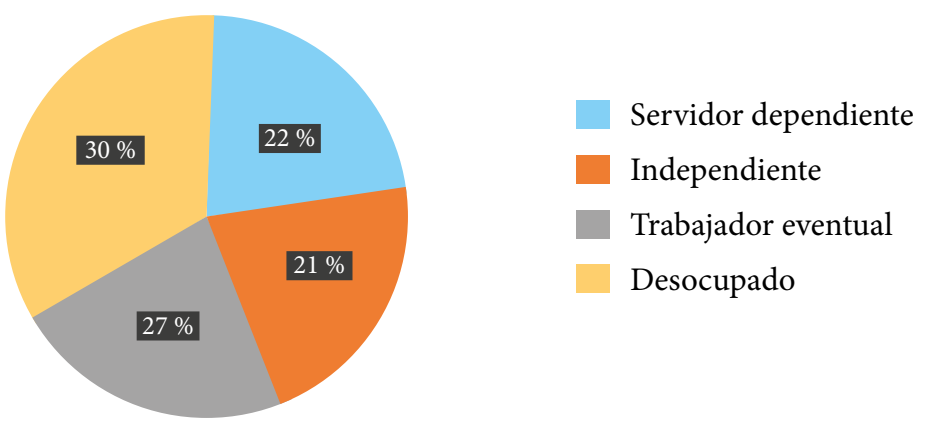

Fuente: Equipo de investigación.

Interpretación: Acumulando los rubros desocupado (30\%) y trabajador eventual (27\%) se obtiene $57 \%$. Al igual que el resto de nuestro país, la desocupación está presente también en Cerro de Pasco. Cabe recordar que se aplicó el instrumento de recolección de datos durante la pandemia provocada por la COVID-19.

\subsubsection{De la identificacion telúrica}

\section{Cuadro y gráfico n. ${ }^{\circ} 8$}

\section{Usted se identifica como integrante de una población}

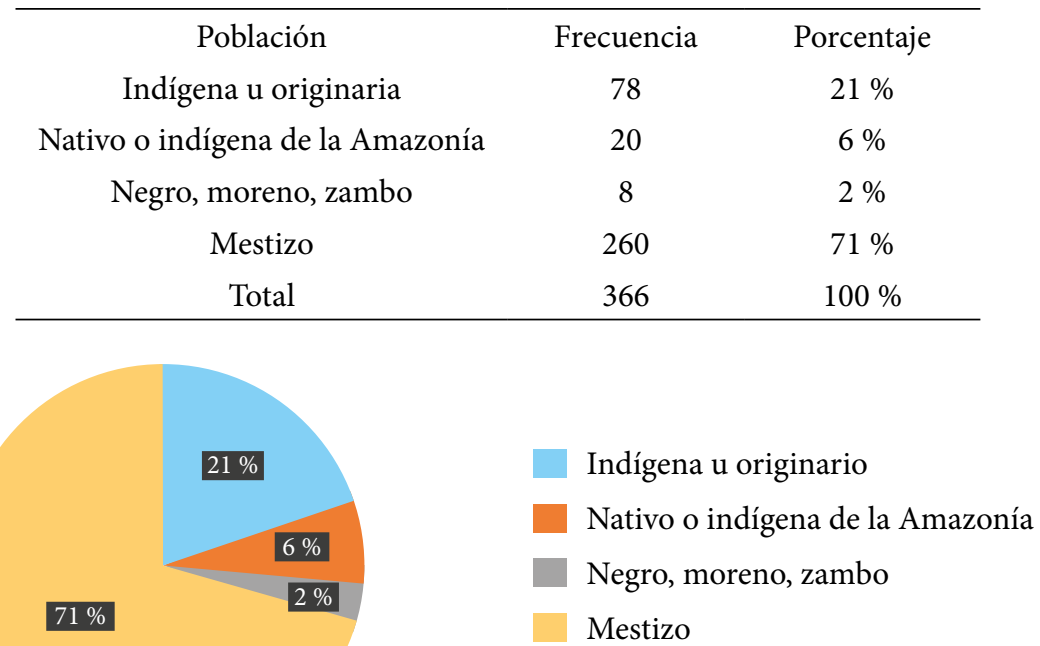

Fuente: Equipo de investigación. 
Interpretación: El 71 \% declaró pertenecer a la población mestiza, este dato se relaciona con la procedencia de los habitantes y también nos permite adelantar su identidad cultural.

\section{Cuadro y gráfico n. ${ }^{\circ} 9$}

¿Cuánto conoce la historia de Cerro de Pasco?

\begin{tabular}{ccc}
\hline Opiniones & Frecuencia & Porcentaje \\
Mucho & 90 & $24 \%$ \\
Poco & 274 & $73 \%$ \\
Nada & 10 & $3 \%$ \\
Total & 366 & $100 \%$ \\
\hline $3 \%$ & & \\
& $24 \%$ & Mucho \\
& & Poco \\
& & \\
\hline
\end{tabular}

Fuente: Equipo de investigación.

Interpretación: El hecho de que casi una cuarta parte de la población señala que conoce mucho de la historia de Cerro de Pasco es un buen indicador para nuestro estudio. El rubro conoce «poco», cuyo espectro abarca el $3 \%$, a nuestro entender se debe a que en la estructura curricular de educación básica regular no se cuenta con temas de la historia local o si los hay, son muy escasos. 
Cuadro y gráfico n. ${ }^{\circ} 10$

¿Conoce las tradiciones de Cerro de Pasco?

\begin{tabular}{ccc}
\hline Opiniones & Frecuencia & Porcentaje \\
Mucho & 66 & $18 \%$ \\
Poco & 284 & $78 \%$ \\
Nada & 16 & $4 \%$ \\
Total & 366 & $100 \%$ \\
\hline & & \\
\hline $4 \%$ & & \\
& & Mucho \\
& & Poco \\
& & \\
& & \\
& & \\
& & \\
& &
\end{tabular}

Fuente: Equipo de investigación.

Interpretación: Es preocupante que el sector que conoce «mucho» haya descendido; los pobladores que señalan conocer "poco» mantienen el nivel alcanzado en la pregunta del cuadro anterior. Efectivamente, la enseñanza escolarizada tiene mucha responsabilidad y no basta con algunas expresiones públicas anuales para conocer $\mathrm{y}$ difundir las tradiciones locales.

\begin{tabular}{ccc}
\multicolumn{3}{c}{ Cuadro y gráfico n. ${ }^{\circ} 11$} \\
¿Le agradan el huaino y la muliza cerreña? \\
\hline Opiniones & Frecuencia & Porcentaje \\
Mucho & 118 & $32 \%$ \\
Poco & 218 & $60 \%$ \\
Nada & 30 & $8 \%$ \\
Total & 366 & $100 \%$ \\
\hline
\end{tabular}




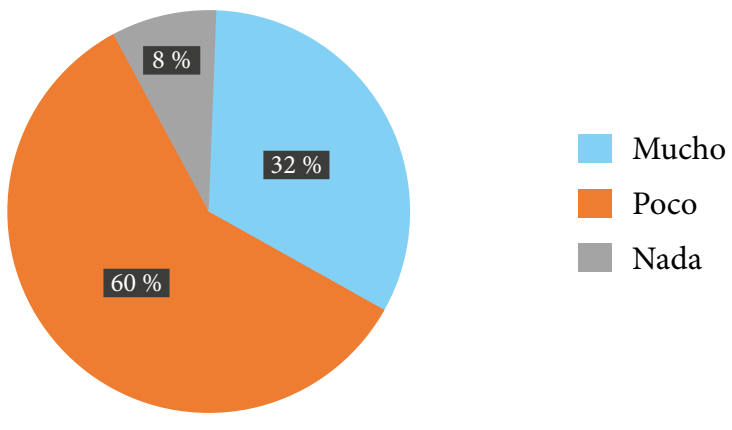

Fuente: Equipo de investigación.

Interpretación: Los ciudadanos cuyas edades oscilan entre 60 años a más indican que le agradan mucho, y la gran mayoría (60\%) indica que poco, esto podría estar dándose por otras influencias musicales. Es conveniente observar que hay un porcentaje, aunque mínimo (8\%), al que no le agrada nada. Las emisoras radiales locales en su parrilla de programación no tienen espacios dedicados a la difusión del huaino y la muliza.

\section{Cuadro y gráfico n. ${ }^{0} 12$}

¿Cuánto sabe sobre la chunguinada cerreña?

\begin{tabular}{ccc}
\hline Opiniones & Frecuencia & Porcentaje \\
Mucho & 81 & $22 \%$ \\
Poco & 230 & $63 \%$ \\
Nada & 55 & $15 \%$ \\
Total & 366 & $100 \%$ \\
\hline & & \\
\hline $15 \%$ & $22 \%$ & Mucho \\
& & Poco \\
& & \\
& & \\
& & \\
& &
\end{tabular}

Fuente: Equipo de investigación. 
Interpretación: La chunguinada cerreña, danza surgida posiblemente en el siglo XVII, no es apreciada hoy en día por la juventud actual. Cuánta diferencia existe entre la preferencia pública con otra danza como la tunantada, por ejemplo, que en menos de treinta años tiene difusión nacional. Nuevamente, el descuido del sector educación está presente. La población no puede preferir y practicar lo que no conoce.

\section{Cuadro y gráfico n. ${ }^{\circ} 13$}

¿Participa en los carnavales cerreños?

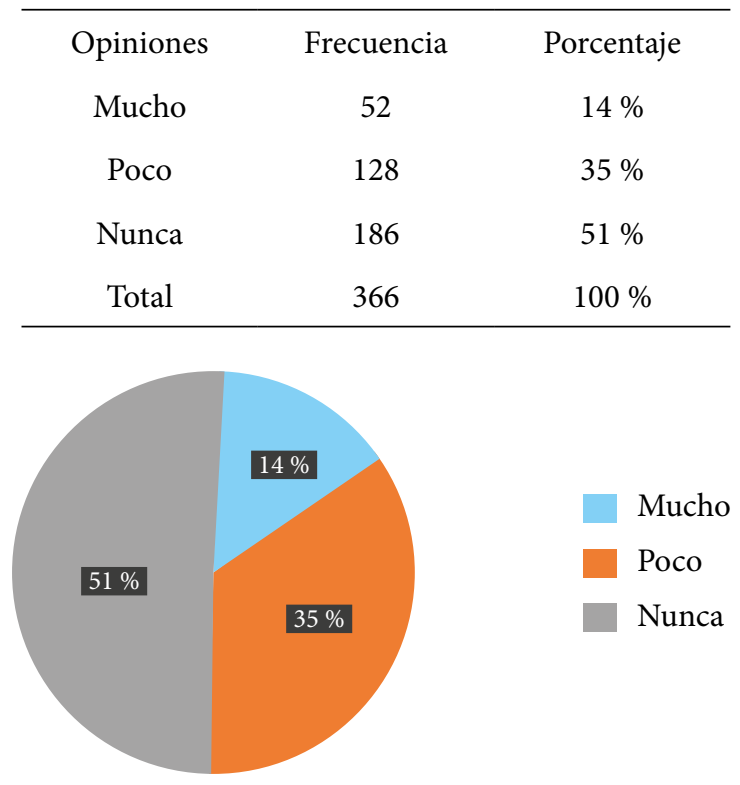

Fuente: Equipo de investigación.

Interpretación: Los resultados mostrados en los cuadros y gráficos $9,10,11$ y 12 ya iban conduciendo a lo que ahora se muestra. El $86 \%$ indica que participa poco o nunca, frente al $14 \%$ que participa mucho. Aquí tenemos otro dato importante sobre la debilidad de la identidad telúrica. 
Cuadro y gráfico n.o 14

\section{La costumbre de «taita compadre» tiene su origen en}

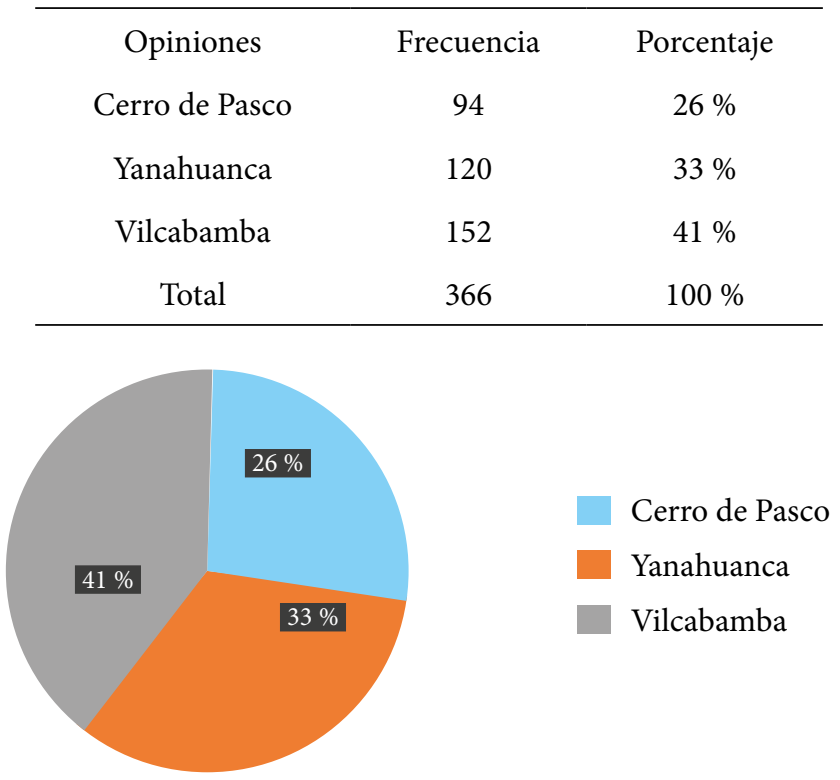

Fuente: Equipo de investigación.

Interpretación: Si unimos las respuestas «Yanahuanca, Vilcabamba», se obtiene un porcentaje muy respetable, porque la costumbre «taita compadre» se practica en Vilcabamba, que es un distrito de la provincia de Daniel Carrión, cuya capital es Yanahuanca. Por la condición de ciudad cosmopolita, Cerro de Pasco tiene muchos habitantes provenientes de esa provincia.

\section{Cuadro y gráfico n.o 15}

El baile «polis polca» se practica en

\begin{tabular}{ccc}
\hline Opiniones & Frecuencia & Porcentaje \\
Yanahuanca & 48 & $10 \%$ \\
Pozuzo & 290 & $59 \%$ \\
Huariaca & 28 & $31 \%$ \\
Total & 366 & $100 \%$ \\
\hline
\end{tabular}




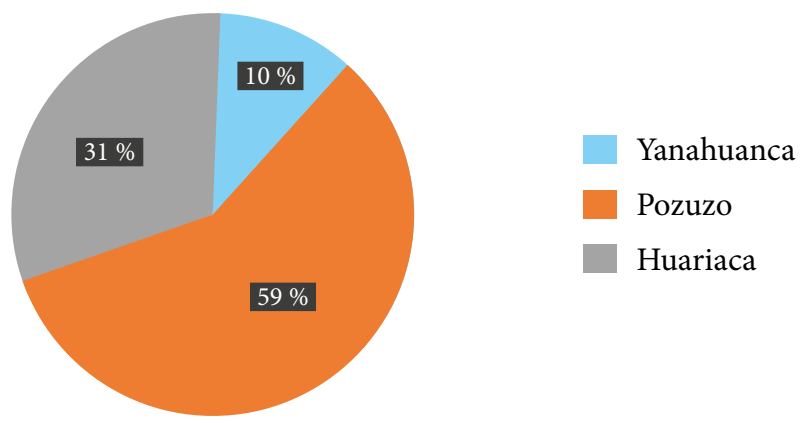

Fuente: Equipo de investigación.

Interpretación: Se consolida nuestra apreciación de que es la enseñanza en educación básica regular la difusora de la cultura local. La UGEL Oxapampa mantiene la política de difundir la cultura de esa parte regional en todos los niveles y modalidades.

\section{Cuadro y gráfico n. ${ }^{\circ} 16$}

El cuento «Mama raihuana» pertenece a

\begin{tabular}{ccc}
\hline Opiniones & Frecuencia & Porcentaje \\
Paucartambo & 145 & $29 \%$ \\
Yarushyacan & 201 & $40 \%$ \\
Chacayan & 20 & $31 \%$ \\
Total & 366 & $100 \%$ \\
\hline $31 \%$ & & \\
& & \\
& & \\
& & \\
& & Paucartambo \\
& & \\
& &
\end{tabular}

Fuente: Equipo de investigación.

Interpretación: El 71 \% está errado. Se supone que como el cuento utiliza una forma de dialecto quechua pueden creer que el origen está en esos dos pueblos campesinos. Lo cierto es que para los 
estudios universitarios concurren muchos jóvenes de la zona de Paucartambo, quienes habrían dado con la información correcta.

\section{Cuadro y gráfico n. ${ }^{\circ} 17$}

\section{La Ley 10030 crea}

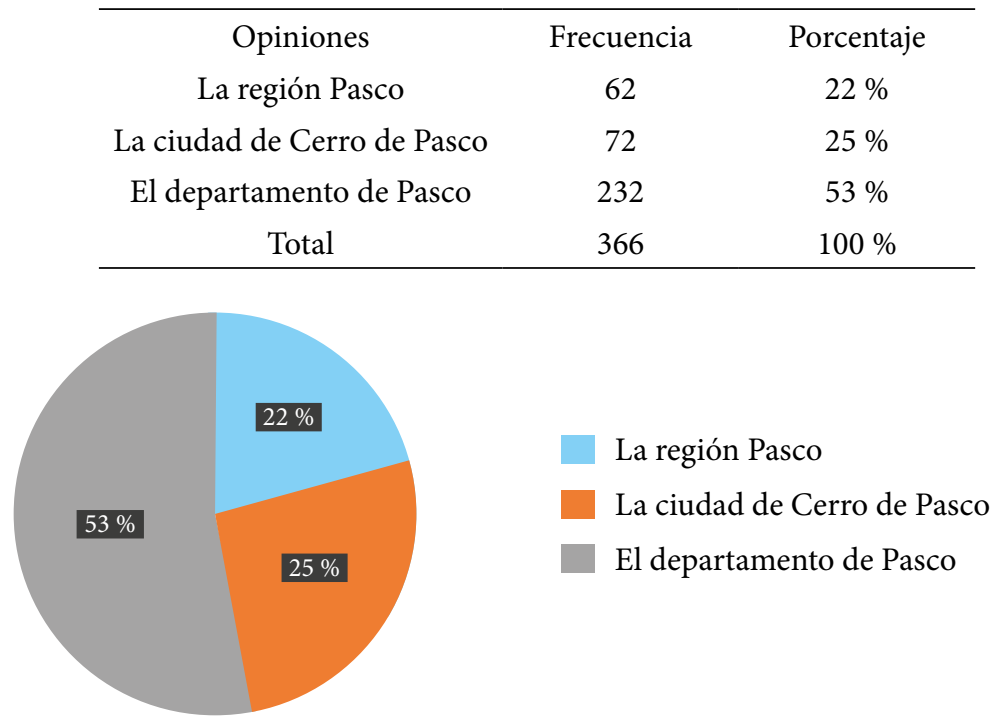

Fuente: Equipo de investigación.

Interpretación: Efectivamente, el conocimiento de los encuestados es loable porque la referida ley crea el departamento de Pasco, con su capital Cerro de Pasco, entonces, el 78 \% está bien informado. Por el manejo actual del término región Pasco puede darse la equivocación en el otro segmento.

Cuadro y gráfico n. ${ }^{\circ} 18$

La festividad «taita Icsha» se celebra

\begin{tabular}{ccc}
\hline Opiniones & Frecuencia & Porcentaje \\
14 de setiembre & 147 & $40 \%$ \\
4 de mayo & 162 & $44 \%$ \\
6 de octubre & 57 & $16 \%$ \\
Total & 366 & $100 \%$ \\
\hline
\end{tabular}




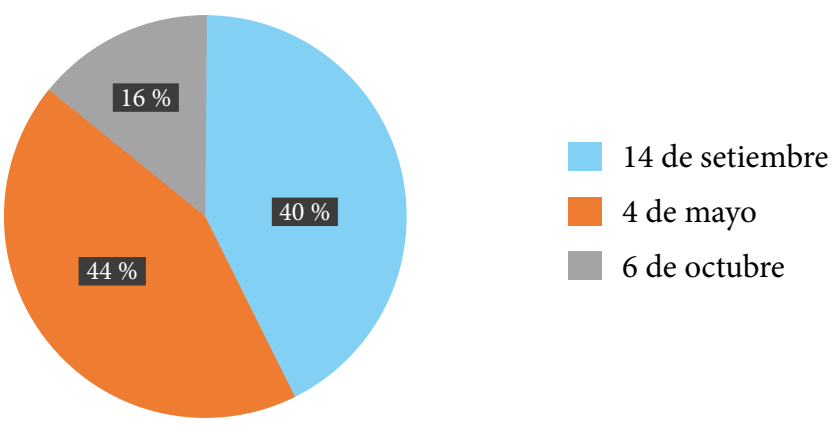

Fuente: Equipo de investigación.

Interpretación: A pesar de que no hay una mayoría que acertó sobre la fecha (14 de setiembre), es importante destacar que un número considerable conoce la fecha de esta festividad.

Cuadro y gráfico n. ${ }^{\circ} 19$

La batalla de Pasco (6 de diciembre de 1820) tuvo como general del ejército patriota a

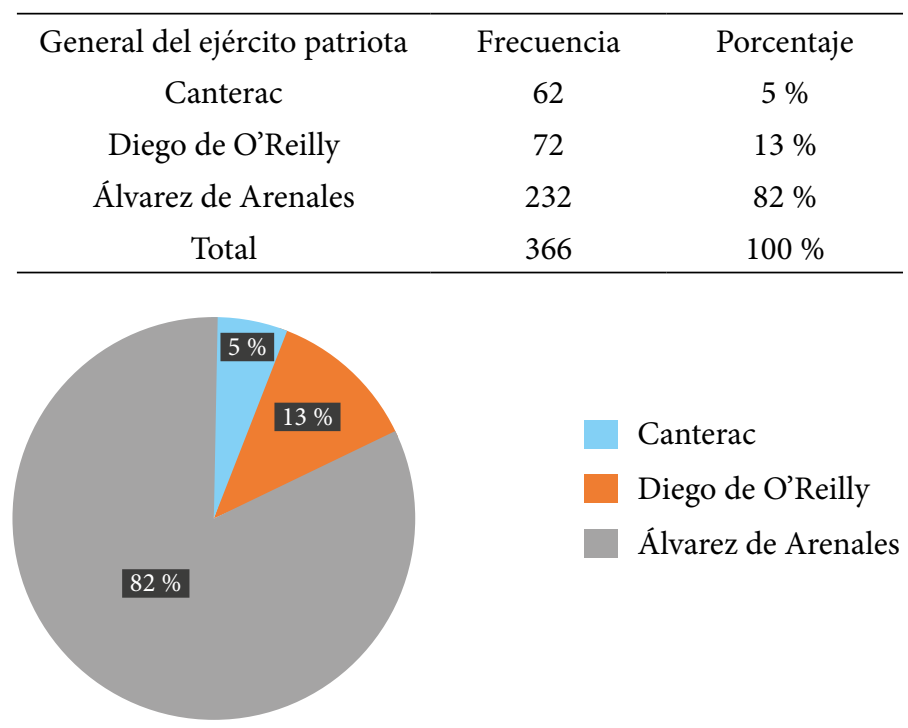

Fuente: Equipo de investigación.

Interpretación: La contundencia de la respuesta mayoritaria (82\%) se explica porque esta fecha conmemorativa sí está considerada en el calendario cívico que se desarrolla en el año académico en 
educación básica regular y básica alternativa. También la universidad, las municipalidades y los institutos superiores programan actividades conmemorativas.

\section{Cuadro y gráfico n. ${ }^{\circ} 20$}

\section{El último distrito que se creó en la región Pasco es}

\begin{tabular}{ccc}
\hline Último distrito & Frecuencia & Porcentaje \\
Tahuarmayo & 82 & $22 \%$ \\
Goyllarisquizga & 98 & $27 \%$ \\
Ciudad Constitución & 186 & $51 \%$ \\
Total & 366 & $100 \%$ \\
\hline & & \\
& & \\
& & \\
& & Tahuarmayo \\
& & Goyllarisquizga \\
& & \\
& &
\end{tabular}

Fuente: Equipo de investigación.

Interpretación: La presencia de la Universidad Nacional Daniel Alcides Carrión en la provincia de Oxapampa, comprensión de la región Pasco, en cuya jurisdicción se encuentra el distrito de Ciudad Constitución, determina que la población conozca su creación. A esto se suma la difusión de la posibilidad de trasladar Cerro de Pasco a ese territorio. 
Cuadro y gráfico n. ${ }^{\circ} 21$

\section{La Universidad Daniel Alcides Carrión fue creada como tal}

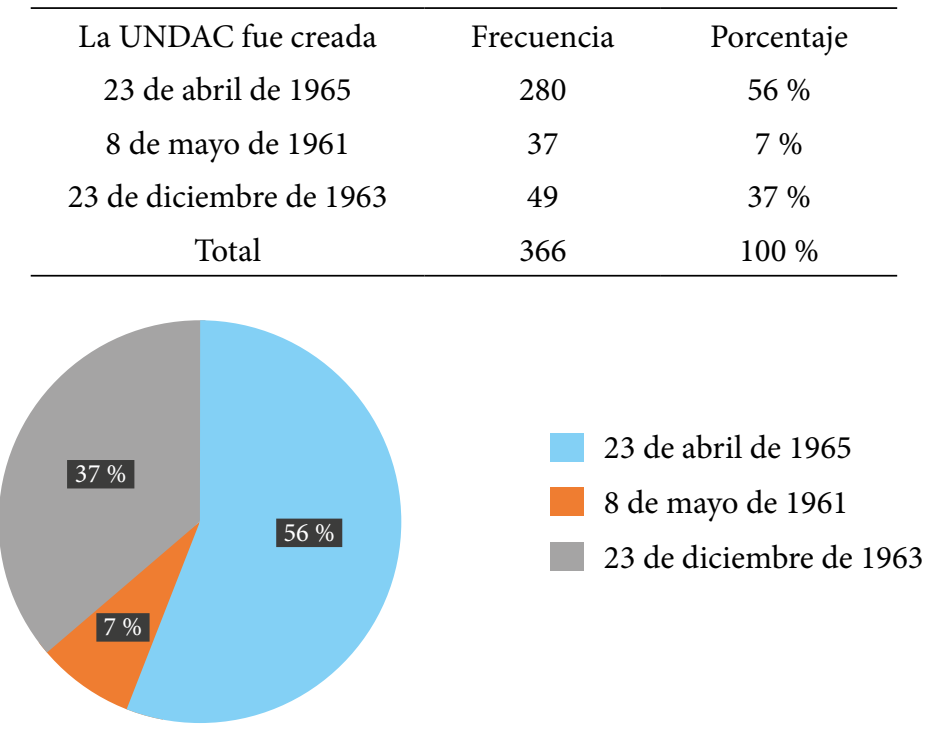

Fuente: Equipo de investigación.

Interpretación: Los estudiantes de todas las carreras profesionales en la Universidad Nacional Daniel Alcides Carrión estudian en el primer semestre, de modo obligatorio, la asignatura Metodología del Trabajo Universitario, que trata sobre el origen y desarrollo de esta institución, razón del conocimiento sobre el particular. Ello se debe también a la edad de los encuestados, que en su mayoría tienen de 18 a 20 años de edad.

\section{Cuadro y gráfico n. ${ }^{\circ} 22$}

\section{La institución educativa de educación primaria más antigua} en Cerro de Pasco es

\begin{tabular}{ccc}
\hline I. E. primaria más antigua & Frecuencia & Porcentaje \\
La Escuela 2850, La Esperanza & 113 & $31 \%$ \\
El Centro Escolar 491 de Patarcocha & 158 & $43 \%$ \\
Las Escuela José Antonio Encinas & 95 & $26 \%$ \\
Total & 366 & $100 \%$ \\
\hline
\end{tabular}




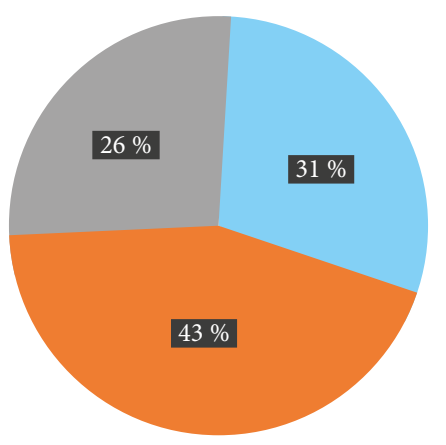

La Escuela 2850, La Esperanza

El Centro Escolar 491 de Patarcocha

La Escuela José Antonio Encinas

Fuente: Equipo de investigación.

Interpretación: Nuevamente, el factor edad de los encuestados tuvo que ver en las respuestas acertadas (43\%).

Cuadro y gráfico n. ${ }^{\circ} 23$

\section{La enfermedad que estudió el mártir Daniel Alcides Carrión fue}

\begin{tabular}{ccc}
\hline $\begin{array}{c}\text { La enfermedad que estudió } \\
\text { Daniel Alcides Carrión }\end{array}$ & Frecuencia & Porcentaje \\
El tifus & 34 & $6 \%$ \\
La verruga & 300 & $58 \%$ \\
La neumonía & 32 & $36 \%$ \\
Total & 366 & $100 \%$ \\
\hline
\end{tabular}

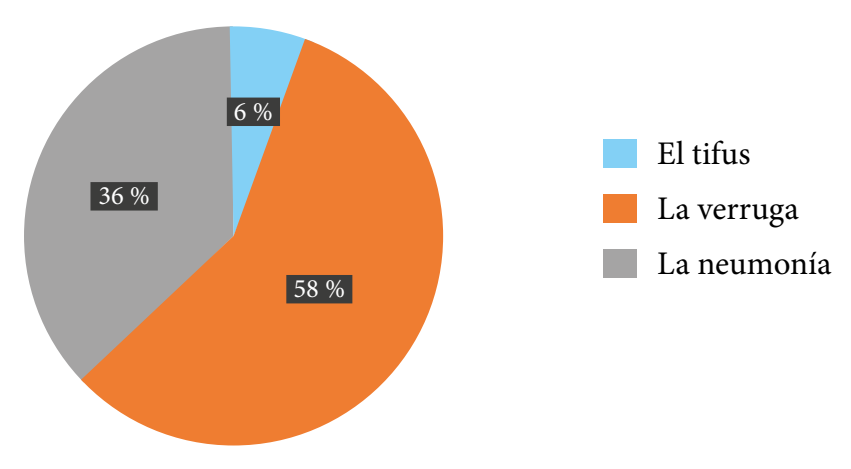

Fuente: Equipo de investigación.

Interpretación: Es importante destacar que, al igual que en los cuatro últimos cuadros, el porcentaje de respuestas acertadas es 
considerable y en este caso supera a más de la mitad, todo debido al grado o nivel educativo, la edad, la procedencia, los años de residencia, entre otros.

\subsubsection{Implicancias de la minería a tajo abierto en los derechos de la población de Cerro de Pasco}

Cuadro y gráfico n. ${ }^{\circ} 24$

¿Está enterado(a) de que la población local sufre estragos por tener plomo en la sangre?

\begin{tabular}{ccc}
\hline Opiniones & Frecuencia & Porcentaje \\
Mucho & 224 & $61 \%$ \\
Poco & 138 & $38 \%$ \\
Nada & 4 & $1 \%$ \\
Total & 366 & $100 \%$ \\
\hline & & \\
\hline & & \\
& & \\
& & \\
& & \\
& & Pucho \\
& &
\end{tabular}

Fuente: Equipo de investigación.

Interpretación: Podemos deducir que la población de Cerro de Pasco sí está consciente de estar afectada por la demasía de plomo en sangre merced a los trabajos mineros por el sistema a tajo abierto. 
Cuadro y gráfico n.o 25

¿2ué derechos considera que se están afectando por la actividad minera a tajo abierto?

\begin{tabular}{|c|c|c|}
\hline Derechos que se afectan & Frecuencia & Porcentaje \\
\hline Derecho a la salud & 226 & $27 \%$ \\
\hline Derecho a la propiedad & 117 & $14 \%$ \\
\hline Derecho a la identidad & 34 & $4 \%$ \\
\hline Derecho a la paz & 88 & $11 \%$ \\
\hline Derecho al desarrollo & 115 & $8 \%$ \\
\hline Derecho al patrimonio cultural & 122 & $15 \%$ \\
\hline Derecho a la educación & 64 & $14 \%$ \\
\hline Otro & 56 & $7 \%$ \\
\hline Total & 366 & $100 \%$ \\
\hline 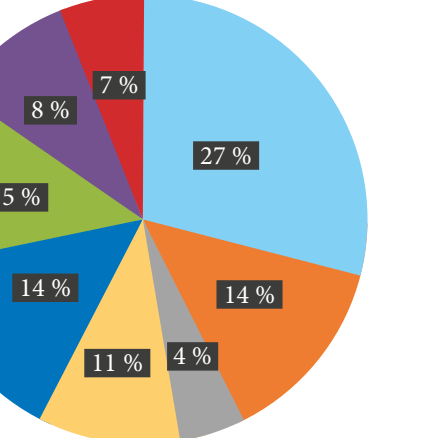 & $\begin{array}{l}\text { Derec } \\
\text { Derec } \\
\text { Derec } \\
\text { Derec } \\
\text { Derec } \\
\text { Derec } \\
\text { Derec } \\
\text { Otro }\end{array}$ & $\begin{array}{l}\text { la salud } \\
\text { la propiedad } \\
\text { la identidad } \\
\text { la paz } \\
\text { l desarrollo } \\
\text { l patrimonio cultural } \\
\text { la educación }\end{array}$ \\
\hline
\end{tabular}

Fuente: Equipo de investigación.

Interpretación: La pregunta formulada posibilitó un abanico de respuestas. Es importante reconocer que, en menor o mayor grado, todos los derechos enunciados se ven afectados. Es posible que por la correlación secuencial, el derecho a la salud esté en el primer lugar $(27 \%)$. 


\section{Cuadro y gráfico n. ${ }^{\circ} 26$}

¿Conoce de algunas acciones que las empresas mineras realizan para mitigar esos daños?

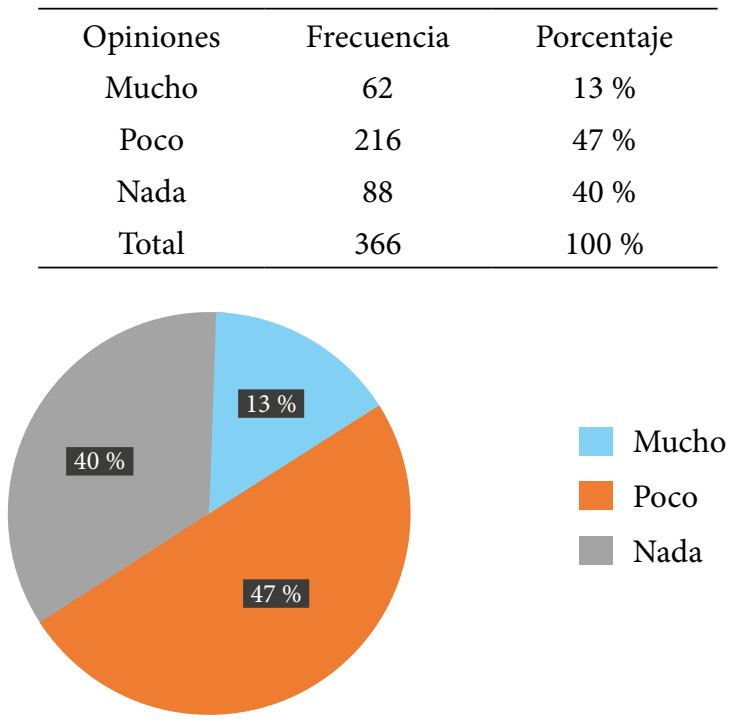

Fuente: Equipo de investigación.

Interpretación: Observando los rubros conoce "poco», «nada», que acumulan $87 \%$, resulta preocupante que no se tengan planes efectivos empresariales para tratar esos temas. Por experiencia directa, diremos que el PAMA (Programa de Adecuación y Manejo Ambiental) es un documento más, sin valor efectivo y que manejan las empresas mineras sin la debida supervisión del sector estatal.

\section{Cuadro y gráfico n. ${ }^{\circ} 27$}

¿Sabe si las autoridades ediles y regionales han tomado acciones sobre la permanente contaminación ambiental local?

\begin{tabular}{ccc}
\hline Opiniones & Frecuencia & Porcentaje \\
Mucho & 12 & $3 \%$ \\
Poco & 216 & $52 \%$ \\
Nada & 138 & $45 \%$ \\
Total & 366 & $100 \%$ \\
\hline
\end{tabular}




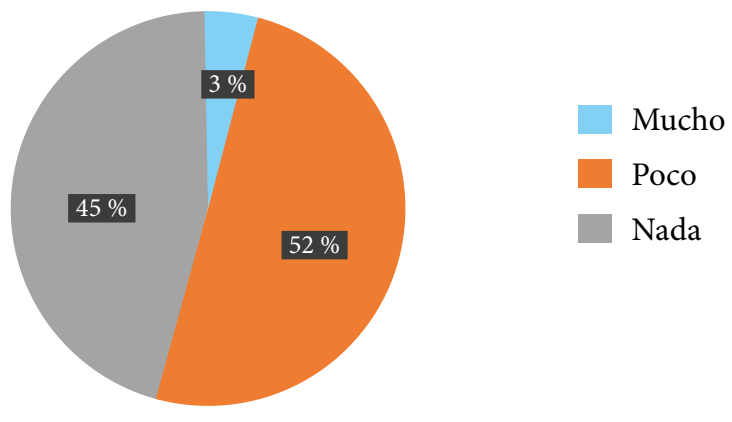

Fuente: Equipo de investigación.

Interpretación: Las respuestas recabadas y que alcanzan $97 \%$ con «poco» y «nada», no solo muestran la desinformación de la población, sino que las autoridades citadas no realizan acciones para mitigar la permanente contaminación ambiental.

\section{Cuadro y gráfico n. ${ }^{\circ} 28$}

¿Está enterado de si el Congreso de la República tiene algún proyecto de ley para cautelar los derechos de los ciudadanos y detener la contaminación ambiental?

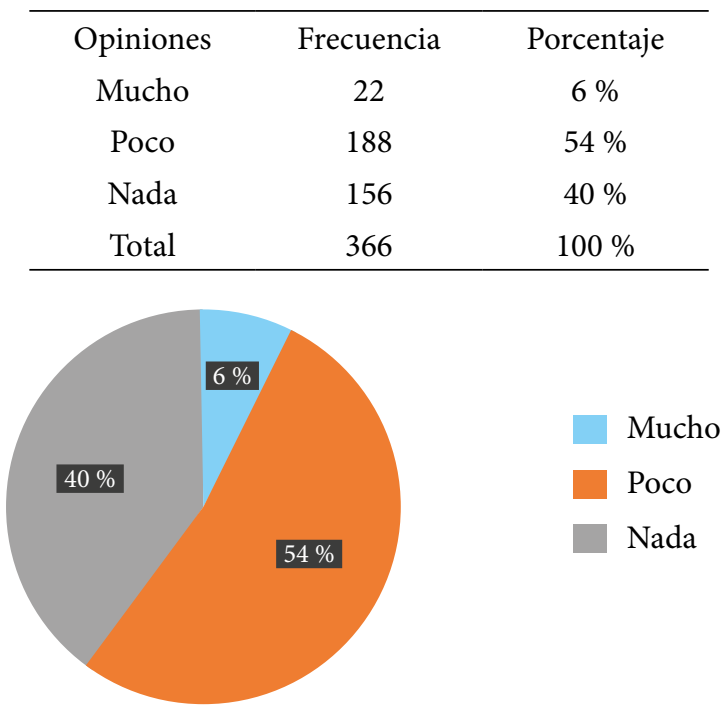

Fuente: Equipo de investigación.

Interpretación: No se trata solamente de que la población sabe poco o nada respecto al trabajo parlamentario sobre este tema. La 
realidad demuestra que al menos en los últimos veinte años no se ha propuesto ni aprobado algún dispositivo sobre el particular.

\section{Cuadro y gráfico n. ${ }^{\circ} 29$}

¿Conoce de algún plan de reubicación definitiva de Cerro de Pasco?

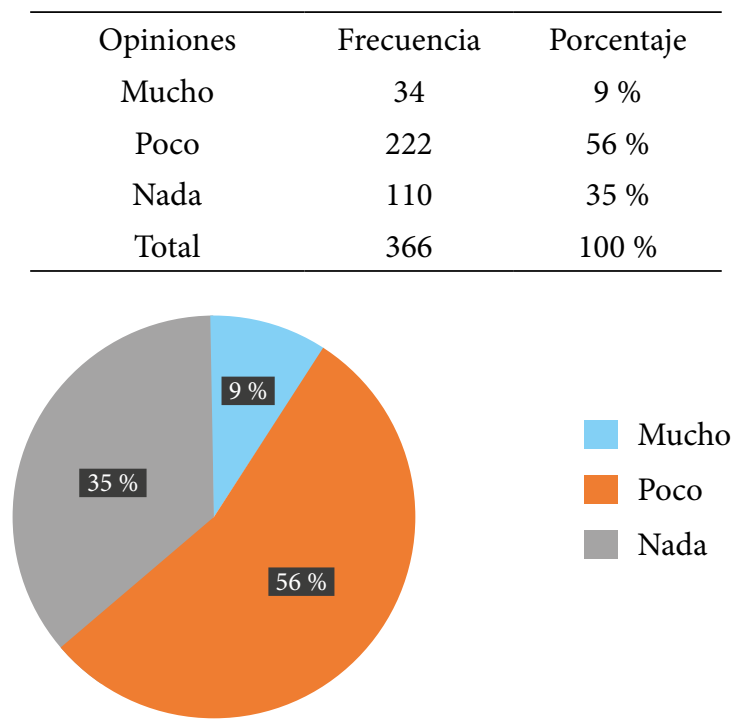

Fuente: Equipo de investigación.

Interpretación: Avalando el porcentaje de $56 \%$, podemos deducir que se refiere al proyecto de traslado de la ciudad de Cerro de Pasco al sector de Villa de Pasco, que data del año 1980 y que fue desestimado por ser antitécnico.

\section{Cuadro y gráfico n. ${ }^{\circ} 30$}

\section{Las gestiones para la reubicación definitiva de Cerro de Pasco deben comenzar}

\begin{tabular}{ccc}
\hline Gestiones para la reubicación & Frecuencia & Porcentaje \\
De inmediato & 162 & $43 \%$ \\
De aquí a 5 años & 78 & $21 \%$ \\
El futuro lo dirá & 126 & $36 \%$ \\
Total & 366 & $100 \%$ \\
\hline
\end{tabular}




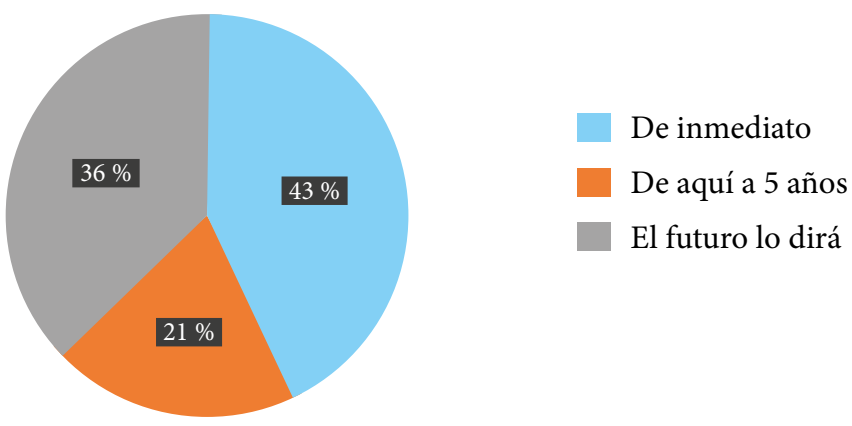

Fuente: Equipo de investigación.

Interpretación: A pesar del olvido gubernamental, la población todavía tiene esperanzas de que la reubicación de la ciudad pueda realizarse en el mediano o corto plazo.

Cuadro y gráfico n. ${ }^{\circ} 31$

¿2uisiera ser consultado sobre la reubicación de la ciudad?

\begin{tabular}{ccc}
\hline Opiniones & Frecuencia & Porcentaje \\
Sí & 298 & $81 \%$ \\
No & 268 & $19 \%$ \\
Total & 366 & $100 \%$ \\
\hline
\end{tabular}

$19 \%$

Sí

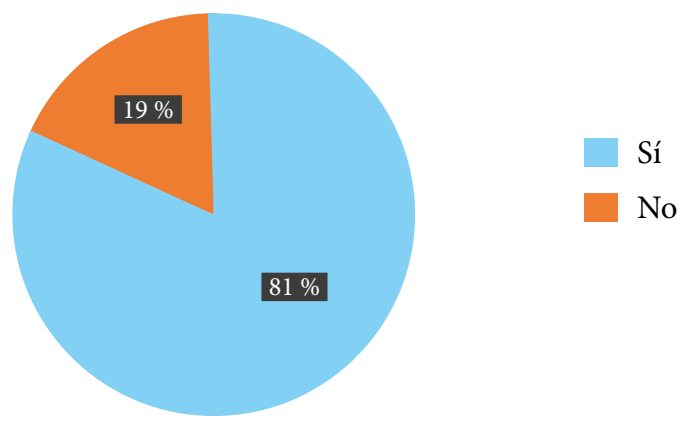

Fuente: Equipo de investigación.

Interpretación: Nuevamente renace la esperanza. Casi el $100 \%$ desea ser consultado. El porcentaje restante está cubierto por ciudadanos de tránsito. 


\section{Cuadro y gráfico n. ${ }^{\circ} 32$}

¿De qué manera considera que se debe decidir la reubicación de la ciudad?

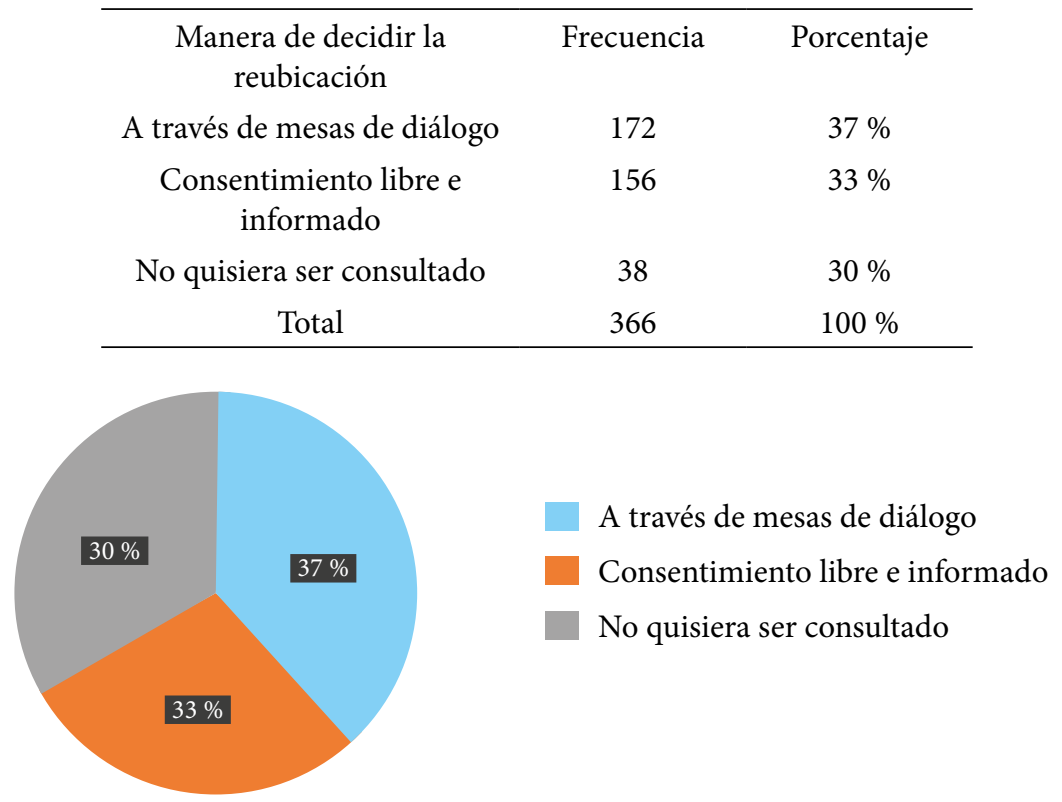

Fuente: Equipo de investigación.

Interpretación: Las dos primeras opciones manifiestan apreciaciones correctas que de ser aplicadas tendrían efectos positivos a partir del conocimiento, participación y decisión de la ciudadanía.

$$
\text { Cuadro y gráfico n. }{ }^{\circ} 33
$$

Si se tratara de que usted elija el lugar de la reubicación, este sería

\begin{tabular}{ccc}
\hline $\begin{array}{c}\text { Lugar de } \\
\text { reubicación } \\
\text { Ciudad }\end{array}$ & Frecuencia & Porcentaje \\
Constitución & 130 & $30 \%$ \\
Villa de Pasco & 164 & $38 \%$ \\
Vicco & 72 & $32 \%$ \\
Total & 366 & $100 \%$ \\
\hline
\end{tabular}




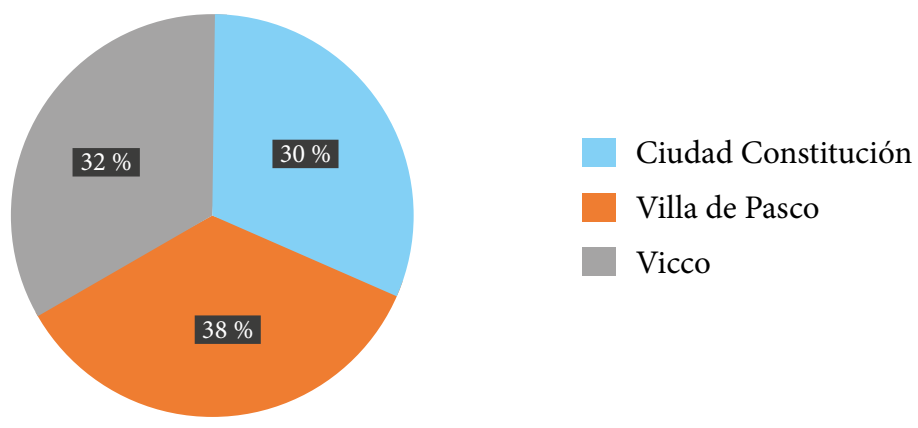

Fuente: Equipo de investigación.

Interpretación: A pesar de las opiniones divididas, resulta positivo que a estas alturas del tiempo ya se considere Ciudad Constitución como una posibilidad. De otra parte, la política de expansión de las autoridades municipales y comunales del distrito de Vicco está animando a muchos pobladores a adquirir terrenos en esa jurisdicción.

Cuadro y gráfico n. ${ }^{\circ} 34$

¿Qué equipo debe gestionar la reubicación?

\begin{tabular}{ccc}
\hline $\begin{array}{c}\text { Equipo que debe gestionar la } \\
\text { reubicación }\end{array}$ & Frecuencia & Porcentaje \\
Comisión multisectorial $a d$ hoc & 50 & $14 \%$ \\
Municipalidad Provincial de Pasco & 110 & $30 \%$ \\
Gobierno regional & 206 & $56 \%$ \\
Total & 366 & $100 \%$ \\
\hline
\end{tabular}

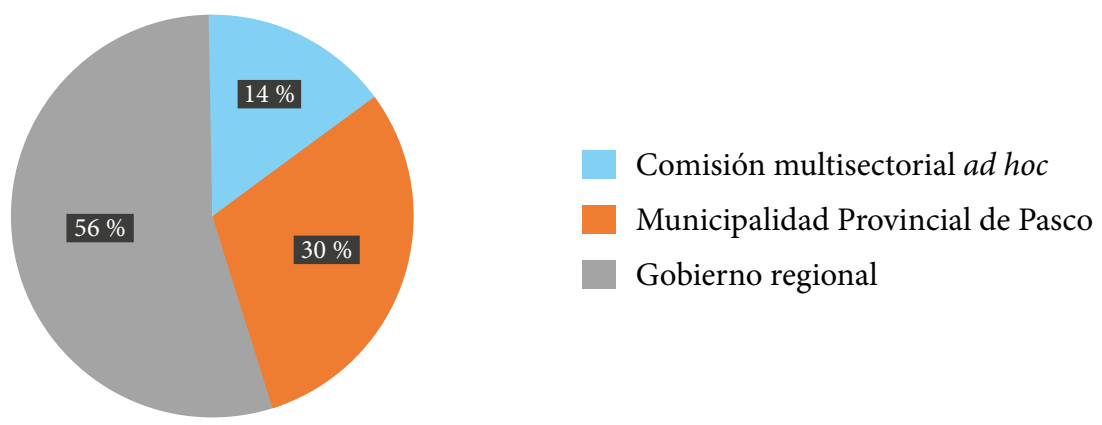

Fuente: Equipo de investigación. 
Interpretación: Entre muchas funciones, los gobiernos regionales tienen competencia sobre modificaciones territoriales. En este sentido, resulta coherente el rubro mayoritario. Dependerá de la inquietud y el conocimiento de los futuros gobernadores.

\section{Cuadro y gráfico n. ${ }^{\circ} 35$}

\section{El costo de la habilitación y la reubicación en sí debe asumirlos}

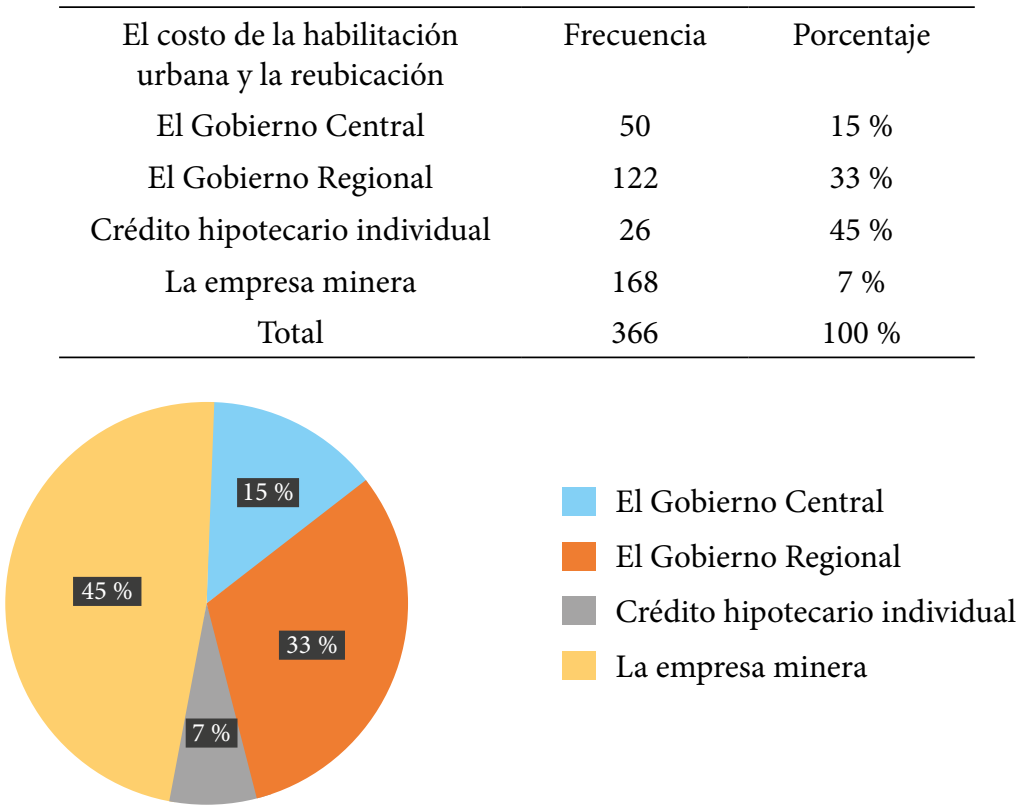

Fuente: Equipo de investigación.

Interpretación: Resulta inaudito que muy pocos ciudadanos reconozcan que la empresa minera, causante de la situación de contaminación, insalubridad y caos urbano, es quien debe responsabilizarse. En el caso hipotético de que la reubicación de la ciudad se haga realidad, ¿algún crédito hipotecario individual alcanzará para costear la construcción y el saneamiento físico legal de una nueva ciudad? 
Cuadro y gráfico n. ${ }^{\circ} 36$

Cree que llevada a cabo la reubicación, la identidad telúrica

\begin{tabular}{ccc}
\hline Identidad telúrica & Frecuencia & Porcentaje \\
Se consolidará & 82 & $22 \%$ \\
Sufrirá otros cambios & 262 & $72 \%$ \\
No pasará nada & 22 & $6 \%$ \\
Total & 366 & $100 \%$ \\
\hline $6 \%$ & & \\
\hline $22 \%$ & & Se consolidará \\
\hline $72 \%$ & & Sufrirá otros cambios \\
& & \\
& & \\
& &
\end{tabular}

Fuente: Equipo de investigación.

Interpretación: La reubicación geográfica necesariamente acarreará muchos cambios personales, sociales y culturales, es decir, incidirá en la identidad telúrica.

\section{Cuadro y gráfico n. ${ }^{\circ} 37$}

El concepto del derecho a vivir bien frente a la reubicación de la ciudad influirá

\begin{tabular}{ccc}
\hline $\begin{array}{c}\text { El concepto del derecho a vivir } \\
\text { bien en la reubicación influirá }\end{array}$ & Frecuencia & Porcentaje \\
Directa y positivamente & 165 & $45 \%$ \\
Medianamente & 153 & $42 \%$ \\
No tendrá mayor injerencia & 48 & $13 \%$ \\
Total & 366 & $100 \%$ \\
\hline
\end{tabular}




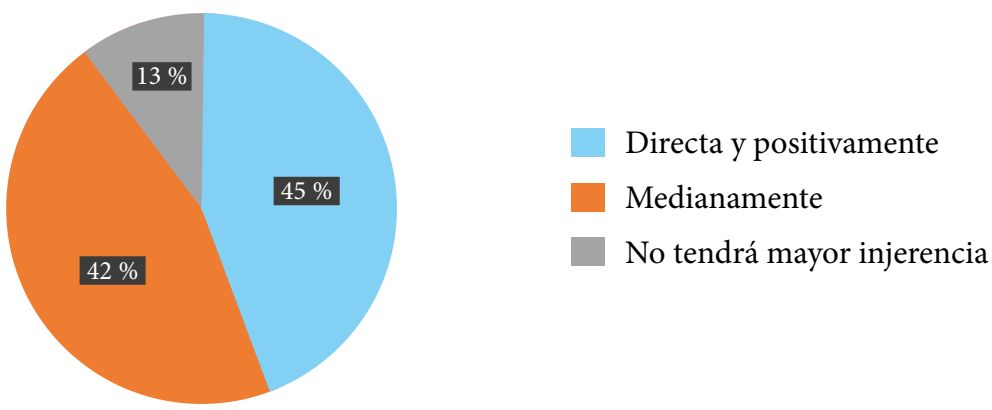

Fuente: Equipo de investigación.

Interpretación: El 87 \% está convencido de la gran influencia del derecho a vivir bien en la reubicación de la ciudad.

\section{Cuadro y gráfico n. ${ }^{\circ} 38$}

¿Cree usted que con la reubicación definitiva de Cerro de Pasco se consolidará el derecho a vivir bien desde el sistema jurídico comunitario?

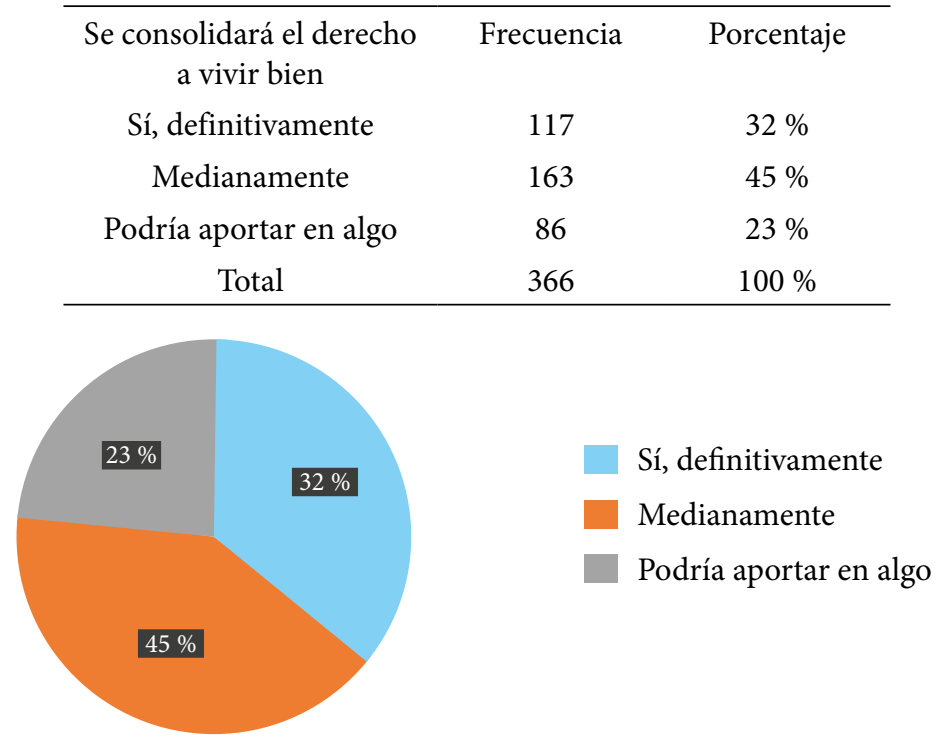

Fuente: Equipo de investigación.

Interpretación: En mayor porcentaje la población considera que el derecho a vivir bien, desde el sistema jurídico comunitario, se consolidará porque, en concordancia con el cuadro precedente, influirá de manera directa y positiva. 


\section{CONCLUSIONES}

1. Queda confirmado que los derechos indígenas u originarios que se afectarían al no aplicarse el derecho a vivir bien, desde el sistema jurídico comunitario, en la reubicación de la ciudad de Cerro de Pasco por efectos de la minería a tajo abierto, son el derecho a la salud, el derecho al patrimonio cultural, el derecho al medio ambiente, el derecho al desarrollo, el derecho a la paz, el derecho a la identidad, el derecho a la propiedad.

2. Consecuentemente, el derecho a la consulta previa garantizará el derecho a vivir bien en la reubicación de la ciudad de Cerro de Pasco por efectos de la minería a tajo abierto, y el derecho al consentimiento libre e informado garantizará el derecho a vivir bien en la reubicación de la ciudad de Cerro de Pasco por efectos de la minería a tajo abierto.

3. La información lograda en los ítems sobre unidades de análisis es totalmente válida y tiene carácter inferencial, muestral para la población dada; en ese sentido, tiene validez y confiabilidad.

4. La identidad telúrica cerropasqueña no está cimentada por la carencia de planes educativos que propicien la práctica de la cultura local y menos porque no se puede negar la influencia externa por la característica de ser una colectividad cosmopolita y por tanto pluricultural. No obstante ello, el $87 \%$ está convencido de la gran influencia del derecho a vivir bien en la reubicación de la ciudad.

5. Está comprobado que la explotación minera por el sistema a tajo abierto en Cerro de Pasco sí contamina el medio ambiente, la salud de sus habitantes; además, genera la desintegración de la unidad urbana y la proliferación de pueblos jóvenes sin orden ni concierto. 
6. El $87 \%$ de la población encuestada desconoce qué acciones y responsabilidades tiene la empresa minera respecto a la contaminación ambiental -PAMA (Programa de Adecuación y Manejo Ambiental)_. Mientras que el $97 \%$ afirma que las autoridades no realizan acciones para mitigar la permanente contaminación ambiental.

7. Queda evidenciado que ni las autoridades locales, ni las regionales, ni el parlamento nacional se preocuparon por tratar este agudo problema desde los ámbitos de su competencia.

8. Queda en la incertidumbre la futura reubicación de lo que queda de la ciudad de Cerro de Pasco porque no se cuenta con planificación alguna. Sin embargo, la población sí manifiesta su preocupación y sugiere la instalación de mesas de diálogo y debates permanentes.

9. La legislación peruana actual no cuenta con herramientas de gestión efectivas para que sean las empresas mineras las que asuman con plena responsabilidad el tratamiento de los impactos ambientales como en otros países.

\section{REFERENCIAS}

Coordinadora Andina de Organizaciones Indígenas (CAOI) (2010). Buen vivir/Vivir bien. Filosofía, políticas, estrategias y experiencias regionales andinas. https://www.escr-net.org/sites/default/ files/Libro\%20Buen\%20Vivir\%20y\%20Vivir\%20Bien_0.pdf

Hernández, R., Fernández, C. y Baptista, M. del P. (2018). Metodología de la investigación. McGraw-Hill; Interamericana Editores. 
Ministerio de Relaciones Exteriores del Estado Plurinacional de Bolivia (2010). Vivir Bien. Mensajes y documentos sobre el Vivir Bien 1995-2010. Ministerio de Relaciones Exteriores.

Montañés, M. y Ramos, E. A. (2012). La paz transformadora: una propuesta para la construcción participada de paz y la gestión de conflictos desde la perspectiva sociopráxica. OBETS. Revista de Ciencias Sociales, 7(2), 241-269.

Pérez Peña, O. A. (2018). Desafíos de la protección jurídica y la gestión del patrimonio cultural ecuatoriano. Revista Lasallista de Investigación, 15(2), 194-209.

Ruiz, N. (2016, enero-junio). Estudio histórico-jurídico del derecho al desarrollo y su potencialidad en los órdenes jurídicos nacionales. Pensamiento Jurídico, (43), 377-403.

Sotomayor, E. y Atay, F. (2018). El medio ambiente desde el discurso y políticas de derechos humanos: una aproximación preliminar al estado de la cuestión. THĒMIS. Revista de Derecho, (74), 139-152.

Taipe, L. P. (1992). Filosofía andina. Escuela de Filosofía Andina; Movimiento Inka.

Tribunal Constitucional (2004). Sentencia del Tribunal Constitucional. Exp. n. ${ }^{\circ}$ 2016-2004-AA/TC. Lima: 5 de octubre de 2004. https://www.tc.gob.pe/jurisprudencia/2005/02016-2004-AA.pdf

Tribunal Constitucional (2005a). Sentencia del Tribunal Constitucional. Exp. n. ${ }^{\circ}$ 0048-2004-PI/TC. Lima: 1 de abril de 2005. https://www.tc.gob.pe/jurisprudencia/2005/00048-2004-AI.pdf

Tribunal Constitucional (2005b). Sentencia del Tribunal Constitucional. Exp. n. ${ }^{\circ}$ 3510-2003-AA/TC Lima. Lima: 13 de abril de 2005. 
Tribunal Constitucional (2006). Sentencia del Tribunal Constitucional. Exp. n. ${ }^{\circ}$ 2002-2006-PC/TC Lima. Lima: 12 de mayo de 2006. https://tc.gob.pe/jurisprudencia/2006/02002-2006-AC.pdf Tribunal Constitucional (2007). Sentencia del Tribunal Constitucional. Exp. n. ${ }^{\circ}$ 1206-2005-PA/TC Loreto. Lima: 20 de abril de 2007. https://www.tc.gob.pe/jurisprudencia/2007/01206-2005 -AA.pdf 